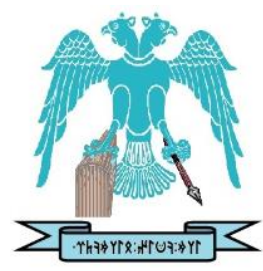

JOURNAL OF ENERGY SYSTEMS

\title{
Improving thermal resistance of lightweight concrete hollow bricks: A numerical optimisation research for a typical masonry unit
}

\author{
Erdem Cuce iD
}

Low/Zero Carbon Energy Technologies Laboratory, Faculty of Engineering, Recep Tayyip Erdogan University, Zihni Derin Campus, 53100 Rize, Turkey

Department of Mechanical Engineering, Faculty of Engineering, Recep Tayyip Erdogan University, Zihni Derin Campus, 53100 Rize, Turkey, erdemcuce@ gmail.com

Pinar Mert Cuce

Low/Zero Carbon Energy Technologies Laboratory, Faculty of Engineering, Recep Tayyip Erdogan University, Zihni Derin Campus, 53100 Rize, Turkey

Department of Energy Systems Engineering, Faculty of Engineering, Recep Tayyip Erdogan University, Zihni Derin Campus, 53100 Rize, Turkey, mertcuce@gmail.com

\section{Ahmet B. Besir}

Low/Zero Carbon Energy Technologies Laboratory, Faculty of Engineering, Recep Tayyip Erdogan University, Zihni Derin Campus, 53100 Rize, Turkey

Department of Mechanical Engineering, Faculty of Engineering, Recep Tayyip Erdogan University, Zihni Derin Campus, 53100 Rize, Turkey, abbesir@gmail.com

$\begin{array}{rr}\text { Submitted: } & 01.08 .2020 \\ \text { Accepted: } & 24.09 .2020 \\ \text { Published: } & 30.09 .2020\end{array}$

Abstract: Heat loss/gain through the walls accounts for about $30 \%$ of the total building energy losses. Bricks are indispensable parts of buildings as a very common masonry wall unit; hence the present work aims at optimising thermal resistance of lightweight concrete hollow bricks through a CFD based numerical research. The optimisation is conducted over a certain number of independent variables such as hollow geometry and design, number of hollow rows across the heat transfer path and hollow depth for natural convection aspects within the hollow enclosure. A reliable CFD software ANSYS FLUENT 18.1 is utilised in the research. The accuracy of the CFD results is justified first through the reference model brick (RMB). Overall heat transfer coefficient (U-value) of RMB is determined to be $0.916 \mathrm{~W} / \mathrm{m} 2$. K, which is in good accordance with the manufacturer's data report $(0.9 \mathrm{~W} / \mathrm{m} 2 . \mathrm{K})$. Following this, parametric research is carried out for various scenarios to optimise the U-value as a function of brick mass. Based on the findings, the maximum improvement is found to be about $53 \%$ (U-value $0.43 \mathrm{~W} / \mathrm{m} 2$. K) through the case of B48 which has an h-ratio of 1 (continuous hollow from top to bottom). Moreover, depending on the increase in h-ratio, it is achieved that the thermal performance of the bricks proportionally increases. The minimum weight of the brick design (B45) is found to be $7.645 \mathrm{~kg}$ and the corresponding $\mathrm{U}$-value is obtained as $0.44 \mathrm{~W} / \mathrm{m} 2$. K.

Keywords: Hollow bricks, Lightweight concrete, Numerical simulation, Thermal insulation, $U$-value

Cite this paper as:

Cuce, E., Cuce, PM., \& Besir, AB., Improving thermal resistance of lightweight concrete hollow bricks: A numerical optimisation research for a typical masonry unit. Journal of Energy Systems 2020, 4(3), 121-144, DOI: 10.30521/jes.775961 


\section{INTRODUCTION}

Throughout the last few decades of the 21 st century, scientists and policymakers have worried about the tremendously higher level of energy consumption around the globe because of limited reserves of energy resources and hazardous effects of energy consumption on environment. Based on the report declared by the International Energy Agency (IEA), the increase in total energy consumption between 1971 and 2014 is approximately 93\% [1]. The greatest part of this increment is attributed to buildings, and in the light of reports from the United Nations Environment Program (UNEP), 40\% of global energy consumption arises from the building sector [2]. Depending on the reports declared by IEA [3], the increase in energy consumption from buildings is found to be nearly $8.5 \%$ between 2010 and 2018. It is also mentioned that the energy consumption based on fossil fuels in buildings accounts for $36 \%$ of total energy used in dwellings, in 2018. Moreover, it is addressed that the buildings settled in European countries are responsible for about $36 \%$ of total greenhouse gas emissions. When the other reports in the scope are analysed, it is seen that not only residential houses but also commercial buildings consume a significant amount of energy to meet heating, cooling, ventilation and lighting demand [4]. Rising comfort conditions of dwellers in indoor environment thanks to the technological advancements also play a vital role in the energy consumption figures of building sector. From this point of view, most of the countries worldwide notably China accept building sector as a primary action plan to mitigate building oriented energy consumption [5]. Buildings are also believed as an ideal target for drastic minimisation of greenhouse gas emissions at global scale [6].

Energy consumption in building sector is mainly driven by space heating (68.4\%) and hot water production (13.6\%) [7]. Cooling is also reported to be in the scope for urgent mitigation of building energy consumption figures in the world. Further reports reveal that space cooling-related energy use shows $60 \%$ rise from 2000 to 2010, which corresponds to $4 \%$ of global energy consumption in 2010 [8]. Remarkable influence of buildings on heating and cooling demand can be easily ascribed to the insufficient thermal insulation performance of building elements such as external walls, windows, roofs and floors [9-15]. In this respect, intensive studies are carried out to improve the thermal insulation performance of the aforesaid building elements notably external walls in a renewable, low-cost and ecofriendly manner [16]. As known, external walls have notably high heat transfer surface area relative to the other parts of building fabric. It is also well-documented that heat losses and gains take place due to temperature difference across the building elements as well as external walls [17]. Bricks are indispensable parts of external walls, and they are widely utilised in new-built structures and retrofit applications from Europe to Asia. From this point, it can be easily asserted that enhancing the existing thermal resistance values of bricks can play a key role in decreasing the amount of energy consumed in building sector. Thermal insulation performance of bricks is notably affected by the materials used in production like clay and concrete $[18,19]$. A low $\mathrm{U}$-value is expected from any type of building element [20], and the brick geometry is of significant relevance to reduce the energy losses through external walls. In this respect, several works are carried out for the thermal performance optimisation of perforated clay [21-23] and concrete [24-26] bricks.

Energy efficiency in buildings is directly affected by the thermal performance of building envelopes since the building elements like bricks considerably influence the heat loss and heat gain in winter and summer, respectively. In literature, two different methods are usually adopted to improve the thermal resistance of the bricks. First approach is to reduce the thermal conductivity of brick material, and the second one is to optimise the geometry of perforated bricks. Martines et al. [27] conduct detailed research on bricks to better understand the thermal properties of concrete bricks. Comprehensive experimental and numerical analyses are carried out for different hollow geometries and filling materials to evaluate their impacts on thermal insulation performance as shown in Figure 1. Based on the findings, the lowest and highest thermal resistances are found to be 0.207 and $1.581 \mathrm{~m}^{2} . \mathrm{K} / \mathrm{W}$, respectively. In other words, the best $\mathrm{U}$-value among the all cases is achieved to be $0.63 \mathrm{~W} /\left(\mathrm{m}^{2} . \mathrm{K}\right)$. In another research, 
thermal properties of hollow bricks filled with air, glass wool, polystyrene balls and recycled polyurethane foams are investigated [28]. The results reveal that mineral wool filled brick design provides $60 \%$ lower U-value in comparison to air filled bricks. Furthermore, the study conducted by del Coz Diaz et al. [29] focus on the non-linear complex heat transfer performance of light concrete hollow bricks by utilising the finite element method (FEM). In this research, not only heat conduction and convection but also radiation is applied to the analysis of the hollow bricks. The findings show that the differences between experimental and numerical results are found to be nearly $2.5 \%$. The researchers also investigate thermal behaviour of multi-holed bricks by adopting FEM. The transfer equation is handled as a non-linearity due to the assumption of the radiation transfer existing within the large recess belonging to bricks. the mesh-size is varied from 7 to $15 \mathrm{~mm}$. As a result of the study, the proposed method could be utilised to determine the thermal performance of lightweight concrete hollow bricks having different geometries [30]. In another research, concrete bricks are modelled in terms of geometric design in order to improve the thermal resistance of the building element [31]. The numerical approach is based on response surface methodology (RSM) and FEM. In the light of the results, the ideal width of the interior space for perforated bricks is determined to be $30 \mathrm{~mm}$. Different types of hollow bricks with the dimensions of $390 \times 190 \times 190 \mathrm{~mm}$ are numerically analysed to clarify the impacts of hollow geometry on the thermal resistance of concrete bricks. The findings point out that the thermal resistance of bricks is improved as the number of air-filled hollow rows within the bricks increases. Moreover, rectangular-shaped hollow bricks have better thermal performance compared to other types (such as circular parallelogram and triangle) [32]. Similar to the aforesaid research, an optimisation study is conducted over 23 different hollow brick cases by Al-Tamimi et al. [33]. One brick is constructed without hollow and researchers conduct analyses to determine the optimum hollow geometry in comparison to the reference case. Based on the analyses, heat transfer is found to reduce significantly as the cavity rate increases. In addition, for bricks having the same hollow ratio, the hollow shape has an effect on decreasing the heat flow through the bricks. In addition, the results reveal that rectangular shapes are more thermally effective than circular ones.

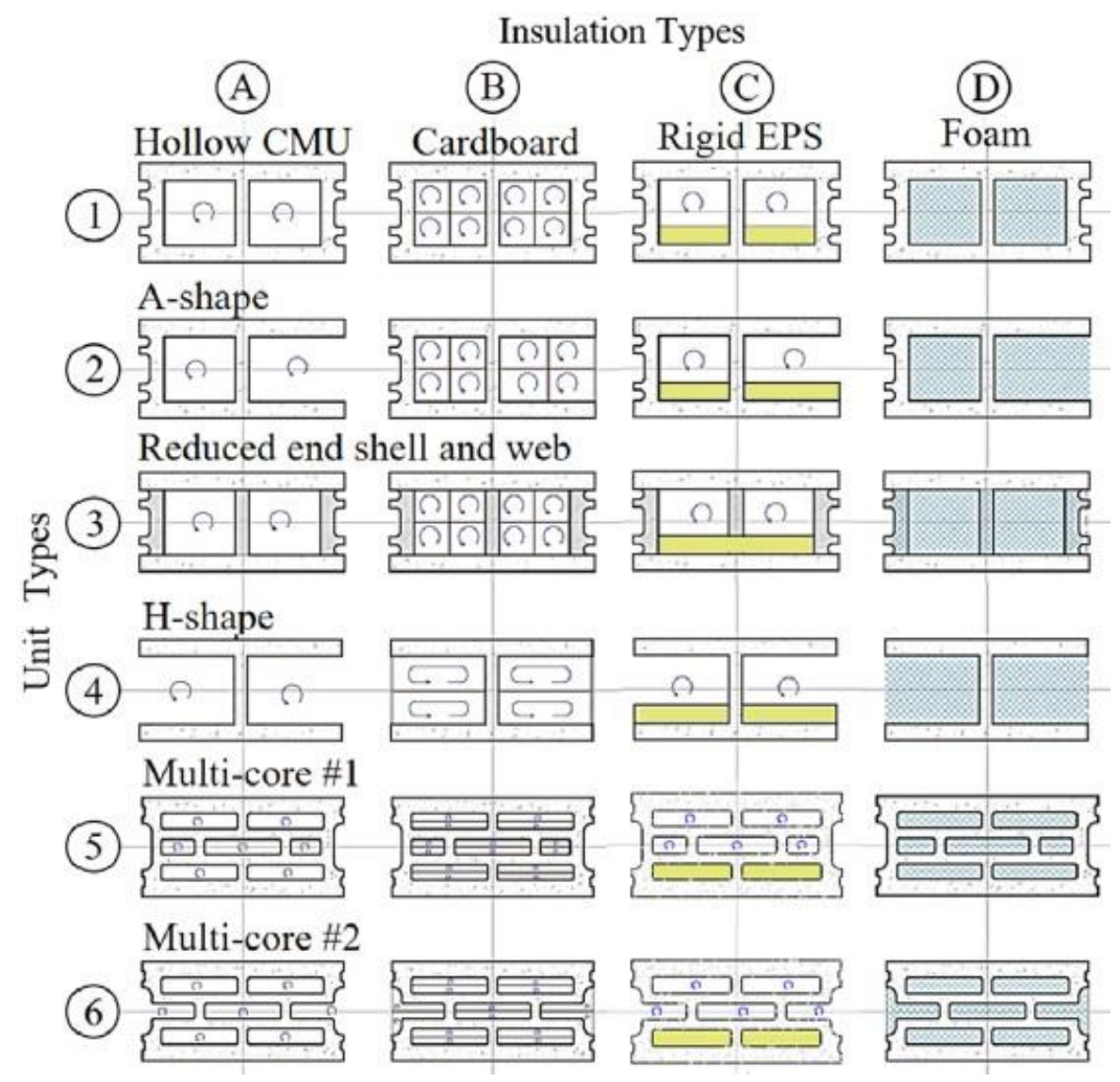

Figure 1. Hollow bricks with different geometric designs and filling materials [26] 
It is unequivocal from the literature survey that external walls are responsible for a significant part of total energy losses from building envelope, and hollow bricks, which are widely utilised in external walls from Europe to Asia are of significant relevance to reduce the aforesaid heat losses. Despite some attempts in previous works, there is not a comprehensive optimisation research in literature for lightweight concrete hollow bricks which aims at enhancing the thermal resistance of the building element by optimising the hollow geometry and number of air-filled hollow rows. Therefore, the present work proposes a numerical strategy based on a parametric research conducted on ANSYS FLUENT 18.1. The research not only aims at reducing $\mathrm{U}$-value with geometric optimisation but also focuses on mitigating brick mass for the entire goal of producing a lightweight thermally resistive building element.

\section{METHODOLOGY}

\subsection{Governing equations}

Within the scope of this research, thermal behaviour of a commercially available lightweight concrete hollow brick is numerically analysed at specified environmental conditions, and then the said product is subjected to an optimisation procedure which aims at maximising thermal resistance while minimising unit mass. To be able to achieve the temperature difference across the product, total heat transfer rate and the U-value, some equations are exploited such as continuity equation, conservation of momentum, and energy equation as given below. In addition, some assumptions are adopted to simplify the analyses as follows:

The flow regime of air within the hollow is steady laminar state.

Air in the hollow is assumed to be incompressible.

Viscous dissipation effects are ignored in the numerical analyses.

All the matter properties are taken to be constant except density.

Density is considered to be as a function of temperature by the following expression proposed for the buoyancy term:

$$
\left(\rho-\rho_{a}\right) g \approx-\rho_{a} \beta\left(T-T_{a}\right) g
$$

where $\rho_{a}$ is the density of air at the ambient temperature of $T_{a}$, and $\beta$ is the thermal expansion coefficient. The abovementioned governing equations can be listed as follows:

Thermal energy conservation equation for solid material:

$$
\frac{\partial}{\partial x}\left(\lambda_{s} \frac{\partial T}{\partial x}\right)+\frac{\partial}{\partial y}\left(\lambda_{s} \frac{\partial T}{\partial y}\right)+\frac{\partial}{\partial z}\left(\lambda_{s} \frac{\partial T}{\partial z}\right)=0
$$

Continuity equation:

$$
\frac{\partial \rho}{\partial t}+\frac{\partial(\rho u)}{\partial x}+\frac{\partial(\rho v)}{\partial y}+\frac{\partial(\partial w)}{\partial z}=0
$$

Momentum equation: 


$$
\begin{gathered}
\frac{\partial(\rho u)}{\partial t}+\frac{\partial(\rho u u)}{\partial x}+\frac{\partial(\rho u v)}{\partial y}+\frac{\partial(\rho u w)}{\partial z}=-\frac{\partial p}{\partial x}+\mu\left(\frac{\partial^{2} u}{\partial x^{2}}+\frac{\partial^{2} u}{\partial y^{2}}+\frac{\partial^{2} u}{\partial z^{2}}\right) \\
\frac{\partial(\rho v)}{\partial t}+\frac{\partial(\rho v u)}{\partial x}+\frac{\partial(\rho v v)}{\partial y}+\frac{\partial(\rho v w)}{\partial z}=-\frac{\partial p}{\partial y}+\mu\left(\frac{\partial^{2} v}{\partial x^{2}}+\frac{\partial^{2} v}{\partial y^{2}}+\frac{\partial^{2} v}{\partial z^{2}}\right) \\
\frac{\partial(\rho w)}{\partial t}+\frac{\partial(\rho w u)}{\partial x}+\frac{\partial(\rho w v)}{\partial y}+\frac{\partial(\rho w w)}{\partial z}=-\frac{\partial p}{\partial z}+\mu\left(\frac{\partial^{2} w}{\partial x^{2}}+\frac{\partial^{2} w}{\partial y^{2}}+\frac{\partial^{2} w}{\partial z^{2}}\right)+\rho g \beta\left(T-T_{a}\right)
\end{gathered}
$$

Energy equation for fluid medium:

$$
\frac{\partial(\rho c T)}{\partial t}+\frac{\partial(\rho c u T)}{\partial x}+\frac{\partial(\rho c v T)}{\partial y}+\frac{\partial(\rho c w T)}{\partial z}=\lambda\left(\frac{\partial^{2} T}{\partial x^{2}}+\frac{\partial^{2} T}{\partial y^{2}}+\frac{\partial^{2} T}{\partial z^{2}}\right)
$$

Boundary conditions:

$$
\begin{array}{cll}
x=0 & u=v=w=0 & \frac{\partial T}{\partial x}=0 \\
x=X 1 & u=v=w=0 & \frac{\partial T}{\partial x}=0 \\
y=0 & u=v=w=0 & \frac{\partial T}{\partial y}=0 \\
y=Y 1 & u=v=w=0 & \frac{\partial T}{\partial y}=0 \\
Z=0 & u=v=w=0 \quad h_{2}\left(T_{f 2}-T_{w 2}\right)=-\lambda_{s} \frac{\partial T}{\partial z} \\
z=Z 1 & u=v=w=0 \quad h_{1}\left(T_{w 1}-T_{f 1}\right)=-\lambda_{s} \frac{\partial T}{\partial z}
\end{array}
$$

U-value:

$$
U=\frac{Q}{A_{s} \Delta T} \quad\left(W / m^{2} \cdot K\right)
$$

U-value refers to the overall heat transfer coefficient across the building element. $Q$ is the total heat transfer rate from hot to cold surface of building element whereas $A_{s}$ is the total heat transfer surface area? $\Delta T$ is the temperature difference between hot and cold surface of building element, and the aforesaid temperatures are numerically determined through the average data.

\subsection{Numerical Simulation}

Many researchers prefer to use two-dimensional (2D) models for determining the thermal performance of hollow bricks [34-38]. For instance, Alhazmy [34] numerically investigates the impacts of using inclined partitions to improve the thermal resistance of hollow bricks via a $2 \mathrm{D}$ model. The results reveal that heat flux across the hollow bricks can be reduced by $37-42 \%$ depending on material and number of partitions. The same model is applied to hollow bricks in which the cavities are filled by polystyrene bars [35]. The results indicate that heat penetration through the hollow bricks can be mitigated by about $36 \%$ with the said design. Antar and Baig [36] numerically analyse the conjugate heat transfer across a hollow brick through a 2D model. Laaroussi et al. [37] numerically evaluate thermal behaviour of hollow bricks through a CFD approach based on finite element method. The model is structured as 2D and covers both conduction, convection and radiation heat transfer modes. Arendt et al. [38] examine the effects of cavity concentration on the thermal insulation performance of hollow bricks via a 2D FEM 
model. They recommend the use of a 3D model in further analyses. It is understood from the previous literature that, a 3D simulation methodology [39-42] is required to accurately investigate the impact of geometric design of hollow bricks on the thermal insulation performance. Therefore, a similar approach is carried out in this research. With the reference brick model (RBM), 49 different models are designed and analysed to optimise the thermal resistance performance of hollow bricks.

In the numerical procedure, lightweight concrete hollow bricks are assumed to be subjected to convective heat transfer both internally and externally. Indoor temperature is considered to be $25^{\circ} \mathrm{C}$, which is commonly preferred as indoor air temperature in winter season. For outdoor temperature, $5{ }^{\circ} \mathrm{C}$ is utilised in the calculations to represent the winter scenario in temperate climatic conditions. Corresponding heat transfer coefficients for indoor and outdoor conditions are taken to be 5 and 25 $\mathrm{W} /\left(\mathrm{m}^{2} . \mathrm{K}\right)$, respectively. Heat transfer is assumed to take place from one direction only across the building element ( $\mathrm{Z}$ direction), and edges are considered to be adiabatic ( $\mathrm{X}$ and $\mathrm{Y}$ directions). Rectangular mesh cells are preferred in the CFD model, and the convergence criterion is selected to be $10^{-5}$ for each governing equations. Model equations are discretised through second order upwind method. Pressure interpolation is supplied by PRESTO technique. Boussinesq approximation is taken into consideration to achieve the change of air density with temperature.

\section{GEOMETRIC OPTIMIZATION}

In $\mathrm{V} 2 \mathrm{G}$ operation, bidirectional AC/DC converter acts as inverter and the energy stored in the battery is given back to the grid. Bidirectional converter with SMC controller in V2G mode of operation is shown in Fig. 14 [7-8]. The error generated is compared with a repetitive waveform of switching frequency 10 A commercially available concrete hollow brick is numerically modelled in the present work via ANSYS FLUENT 18.1. The aim of the CFD research can be described as maximising thermal resistance of the building element through geometric optimisation of hollows, and minimising the entire mass of the element to achieve a lightweight masonry unit at the end of the analyses. The dimensions of the aforesaid commercial building element, which is called as reference model brick (RMB) in the rest of the research are depicted in Figure 2.

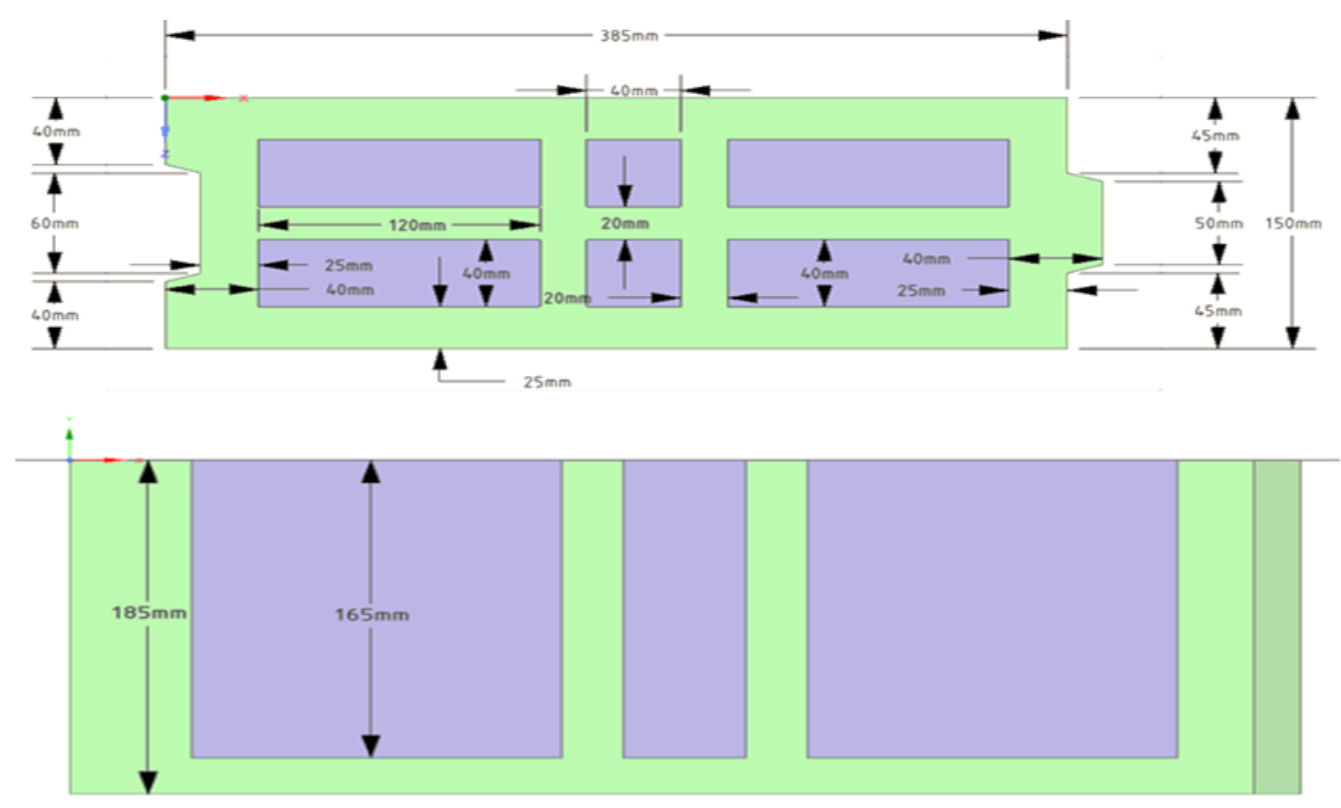

Figure 2. Schematic representation of the commercially available perforated brick.

To be able to conduct the CFD analyses, thermophysical properties required for the research such as density, specific heat capacity and thermal conductivity of the brick material are obtained from the 
manufacturer, and the data is verified by the preliminary tests in the research laboratory. The said data is provided in Table 1. The concrete commonly used to make concrete hollow bricks is a mixture of powdered Portland cement, sand, gravel and water. This yields a light grey block with a fine surface texture and a high compressive strength.

Table 1. Thermal properties of the concrete material

\begin{tabular}{cccc}
\hline & Density $\left(\mathrm{kg} / \mathrm{m}^{3}\right)$ & Specific heat $(\mathrm{J} /(\mathrm{kg} . \mathrm{K}))$ & Thermal conductivity $(\mathrm{W} /(\mathrm{m} . \mathrm{K}))$ \\
\hline Concrete properties & 1500 & 900 & 0.21 \\
\hline
\end{tabular}

Based on the thermal properties of the brick material, a CFD model is constructed, and three different mesh scenarios are adopted to evaluate the accuracy and coherency of the findings as shown in Table 2. For each mesh scenario, total heat transfer rate across the RMB, average hot surface temperature of RMB ( $\left.T_{\max }\right)$, average cold surface temperature of RMB $\left(T_{\min }\right)$, temperature difference across the product $(\Delta \mathrm{T})$ are numerically determined. Finally, over the actual heat transfer surface area of RMB $(0.07122$ $\mathrm{m}^{2}$ ), overall heat transfer coefficient (U-value) is obtained. The results reveal that mesh-independent solution is achieved in model 3 and it exhibits the best fit with the manufacturer's data report, thus this model is taken to be reference model (RM), and the rest of the performance comparisons are done over RM. Static contours of temperature within the entire 3D RMB are illustrated in Figure 3.

Table 2. Mesh-independent solution and corresponding U-values belonging to the brick models

\begin{tabular}{|c|c|c|c|c|c|c|c|c|c|}
\hline Model & $\begin{array}{l}\text { Heat transfer } \\
\text { rate }(\mathrm{W})\end{array}$ & $\begin{array}{c}\text { Surface } \\
\text { area } \\
\left(\mathrm{m}^{2}\right)\end{array}$ & $\begin{array}{l}\mathrm{T}_{\max } \\
(\mathrm{K})\end{array}$ & $\mathrm{T}_{\min }(\mathrm{K})$ & $\begin{array}{l}\Delta \mathrm{T} \\
(\mathrm{K})\end{array}$ & $\begin{array}{c}\text { U-value } \\
\left(\mathrm{W} /\left(\mathrm{m}^{2} \cdot \mathrm{K}\right)\right)\end{array}$ & $\begin{array}{l}\text { Mesh-size } \\
(\mathrm{mm})\end{array}$ & $\begin{array}{c}\text { Cell } \\
\text { number }\end{array}$ & $\begin{array}{l}\text { Iteration time } \\
\qquad(\min )\end{array}$ \\
\hline Model 1 & 1.163 & 0.071 & 296.050 & 278.537 & 17.513 & 0.932 & 9 & 394,849 & 15 \\
\hline Model 2 & 1.159 & 0.071 & 296.249 & 278.523 & 17.722 & 0.918 & 5 & 445,627 & 22 \\
\hline Model 3 & 1.157 & 0.071 & 296.252 & 278.523 & 17.728 & 0.916 & 3 & 526,351 & 25 \\
\hline
\end{tabular}

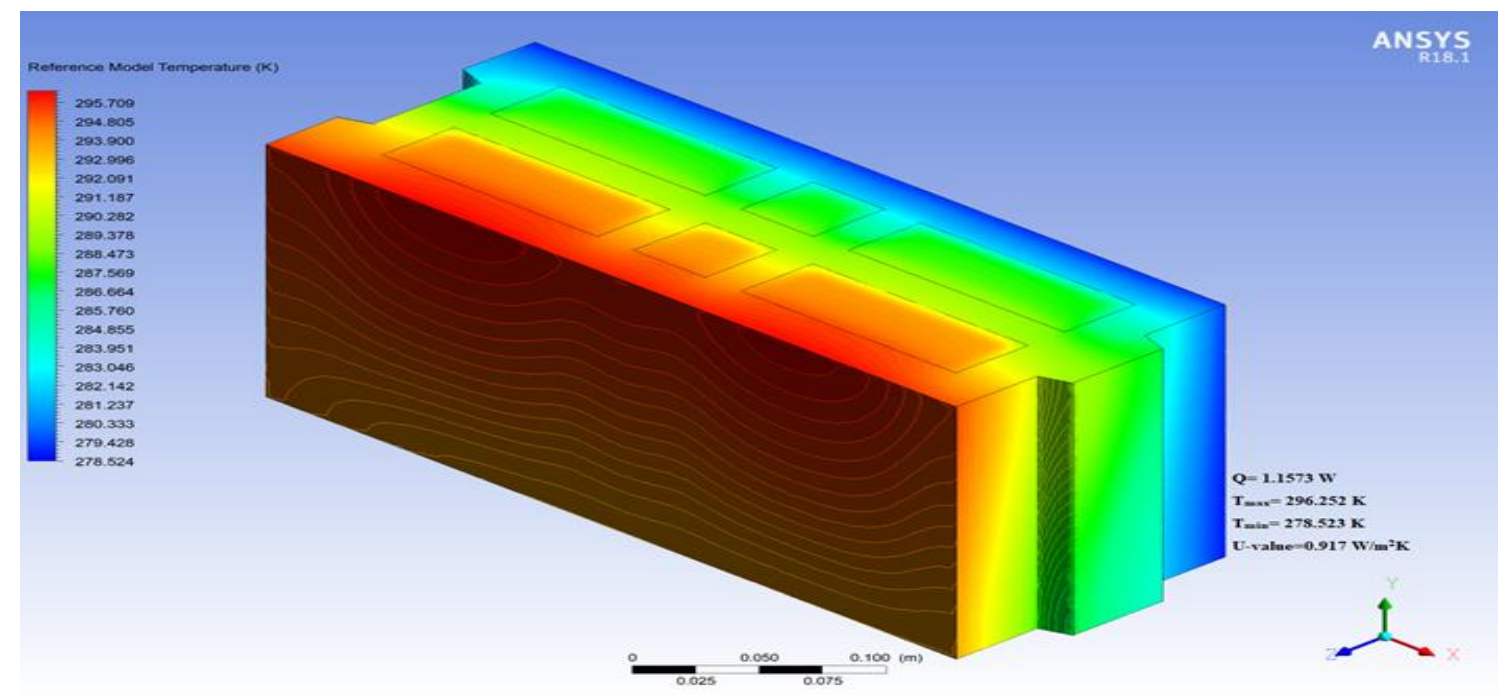

Figure 3. Static contours of temperature of RM and the $U$-value calculation.

\section{RESULTS and DISCUSSION}

\subsection{Design of Hollow Rows}

When carrying out the geometric optimisation of hollow bricks for increasing the thermal resistance while minimising the unit mass, model 3 is considered as RM as previously mentioned, and the 
enhancement strategy is firstly conducted upon optimising the number of hollows within RMB. By doing so, it needs to be noted that the major dimensions of the commercial product are taken to be constant. In this respect, 3, 4 and 5 rows of hollows are considered in the CFD research as shown in Figure 4 to have an understanding about their potential influence on heat flow. 9 different hollow geometries are studied in this part of the research, and the U-values are compared with the case of RM as depicted in Table 3. Among the hollow designs considered, the maximum improvement in thermal insulation performance is achieved through the case of B9 with $38 \%$. With respect to the results, it is clearly deduced that the U-value of hollow bricks considerably depends on the geometry and row numbers of the hollows. Heat conduction in brick material can be equated with the flow of current in an electrical circuit. It is unequivocal that current is keen on following the path with minimum resistance, which is exactly the same with the behaviour of heat flow within the brick material. There is a natural air medium within hollows, and the thermal conductivity of air is remarkably lower than the concrete. From this point of view, increasing the air enclosures within the entire brick, and extending the path of heat penetration from hot to cold surface can be expressed as the goal of the optimisation research.

Table 3. The improvement in thermal performance with respect to 9 different configurations

\begin{tabular}{ccccccc}
\hline Model & Heat transfer rate $(\mathrm{W})$ & $\mathrm{T}_{\max }(\mathrm{K})$ & $\mathrm{T}_{\min }(\mathrm{K})$ & $\Delta \mathrm{T}(\mathrm{K})$ & $\mathrm{U}$-value $\left(\mathrm{W} /\left(\mathrm{m}^{2} . \mathrm{K}\right)\right)$ & Improvement $(\%)$ \\
\hline RM & 1.157 & 296.252 & 278.523 & 17.728 & 0.916 & --- \\
B1 & 0.961 & 296.883 & 278.403 & 18.480 & 0.731 & 20.265 \\
B2 & 0.935 & 296.920 & 278.403 & 18.516 & 0.709 & 22.614 \\
B3 & 0.935 & 296.927 & 278.402 & 18.524 & 0.709 & 22.631 \\
B4 & 0.914 & 296.975 & 278.395 & 18.580 & 0.691 & 24.635 \\
B5 & 0.863 & 296.651 & 278.474 & 18.177 & 0.667 & 27.211 \\
B6 & 0.859 & 296.724 & 278.437 & 18.286 & 0.660 & 28.001 \\
B7 & 0.859 & 296.736 & 278.443 & 18.293 & 0.660 & 28.021 \\
B8 & 0.857 & 296.731 & 278.439 & 18.292 & 0.658 & 28.173 \\
B9 & 0.755 & 297.134 & 278.358 & 18.776 & 0.564 & 38.380 \\
\hline
\end{tabular}
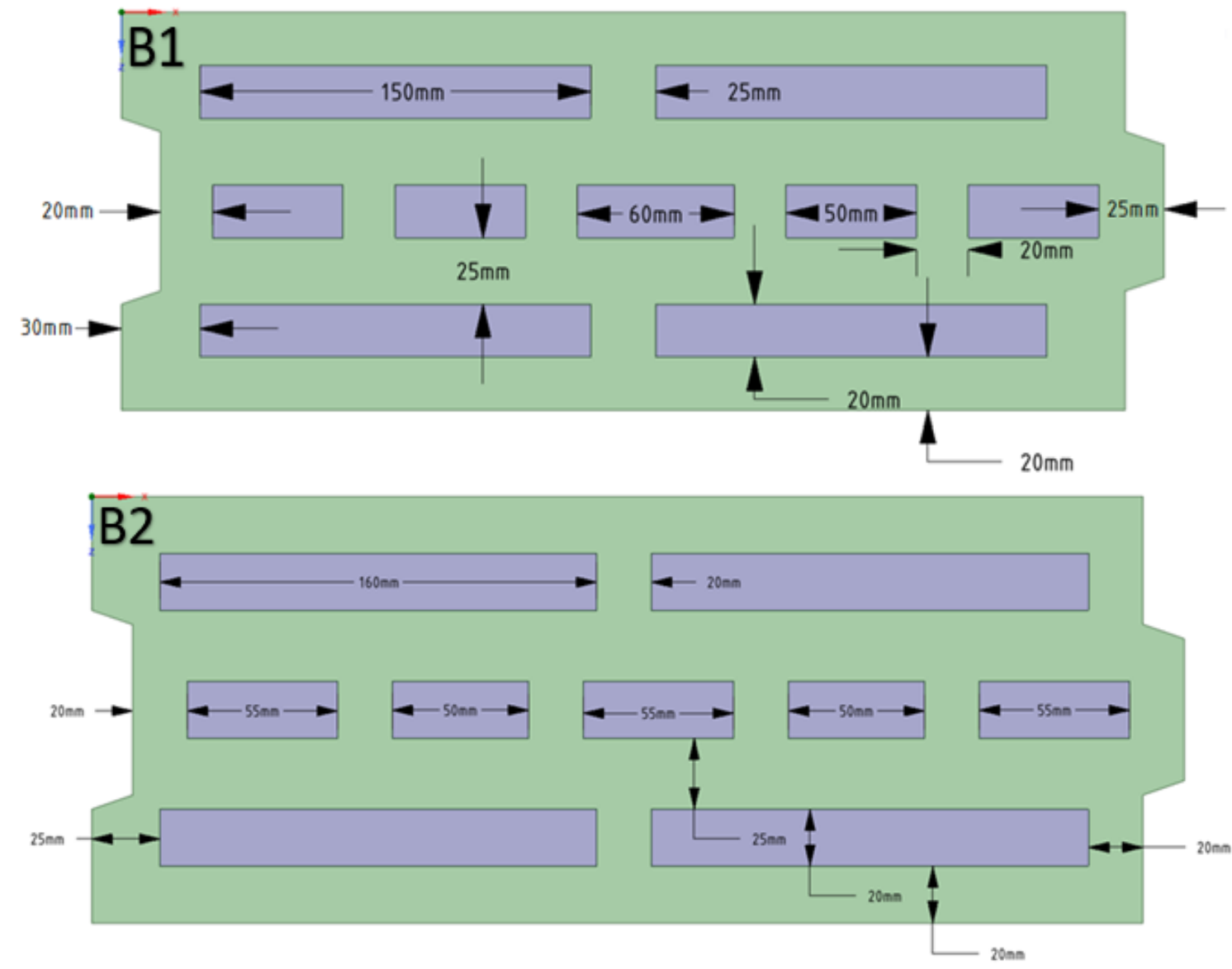

Figure 4. Continues 

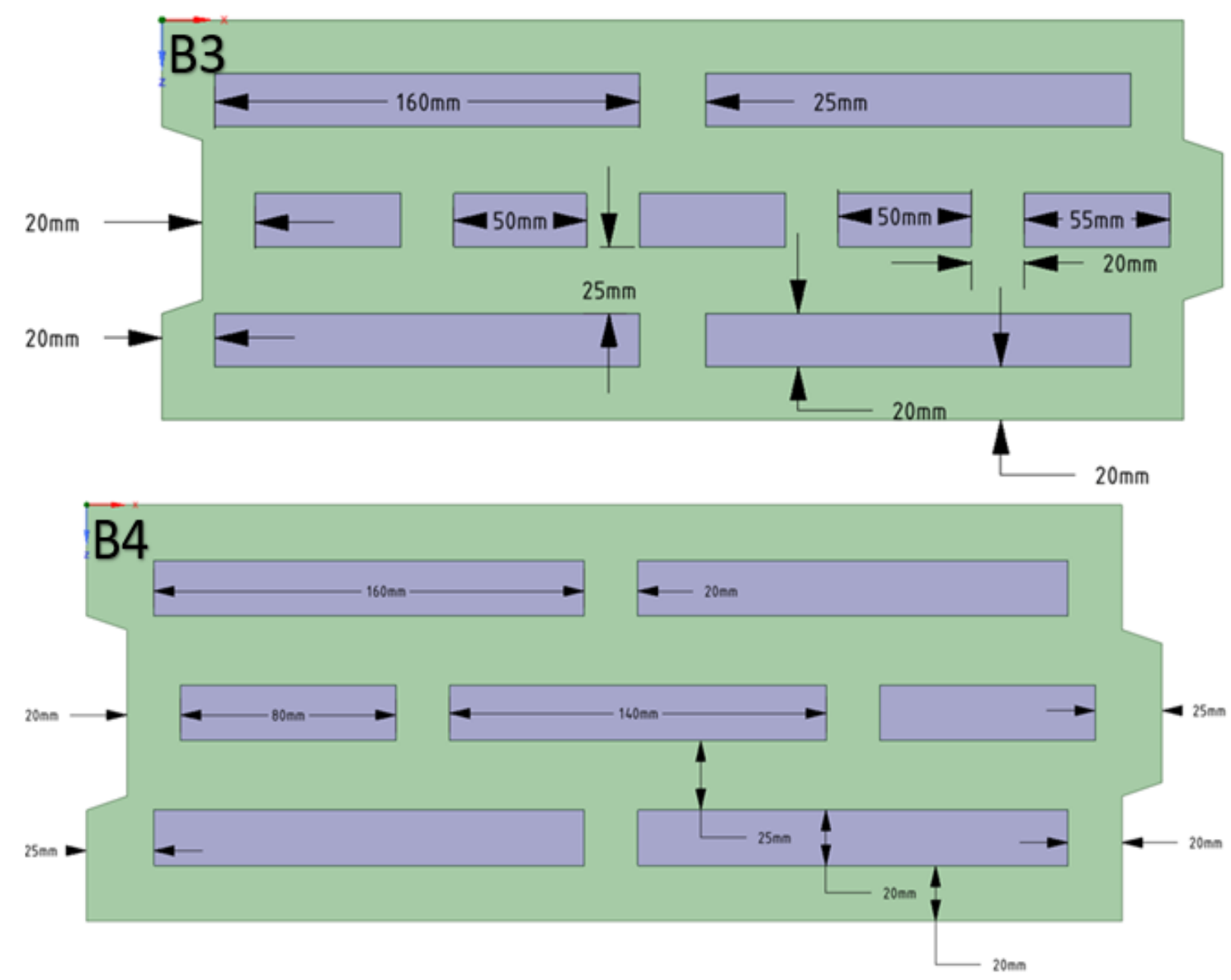

B5
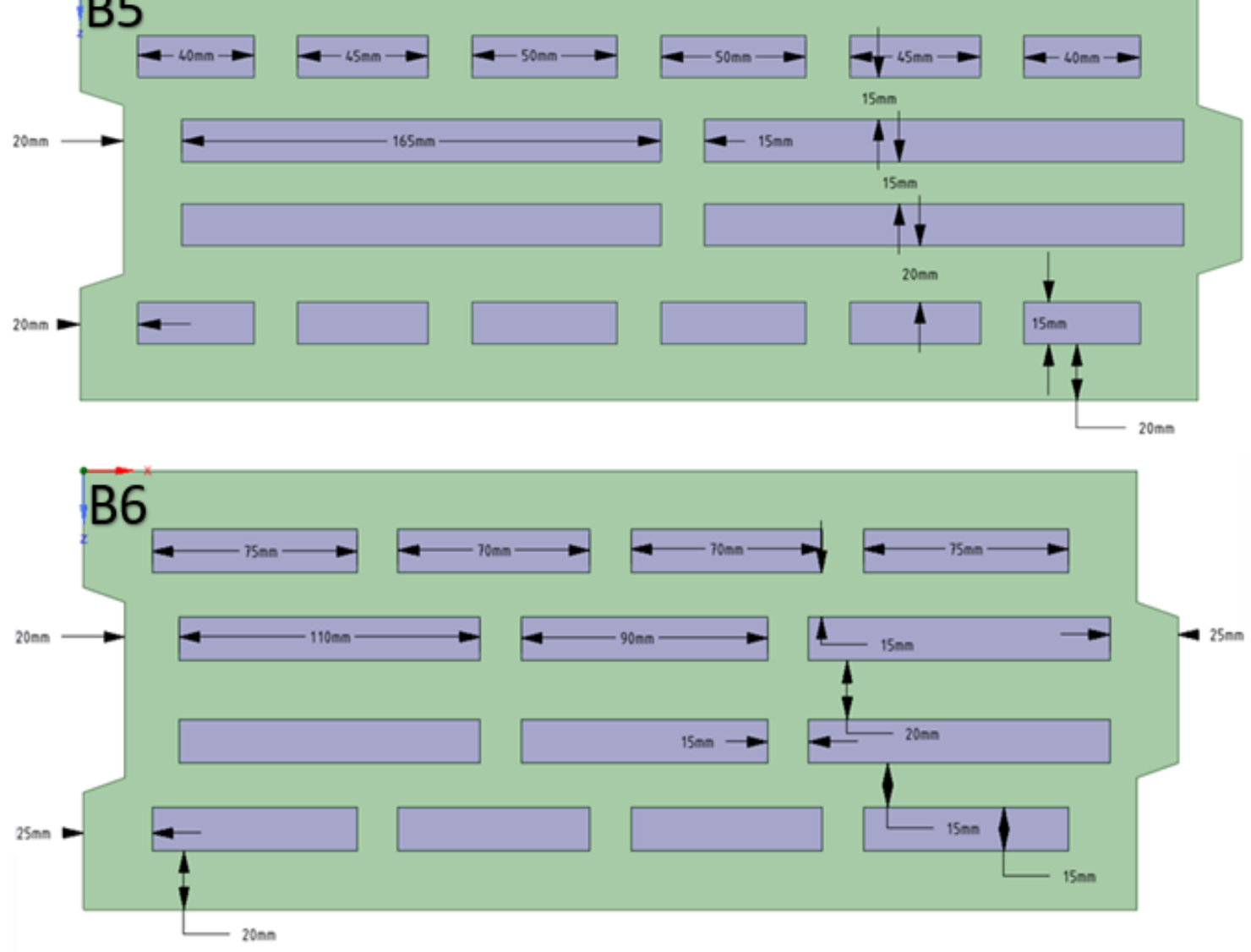

Figure 4. Continues 

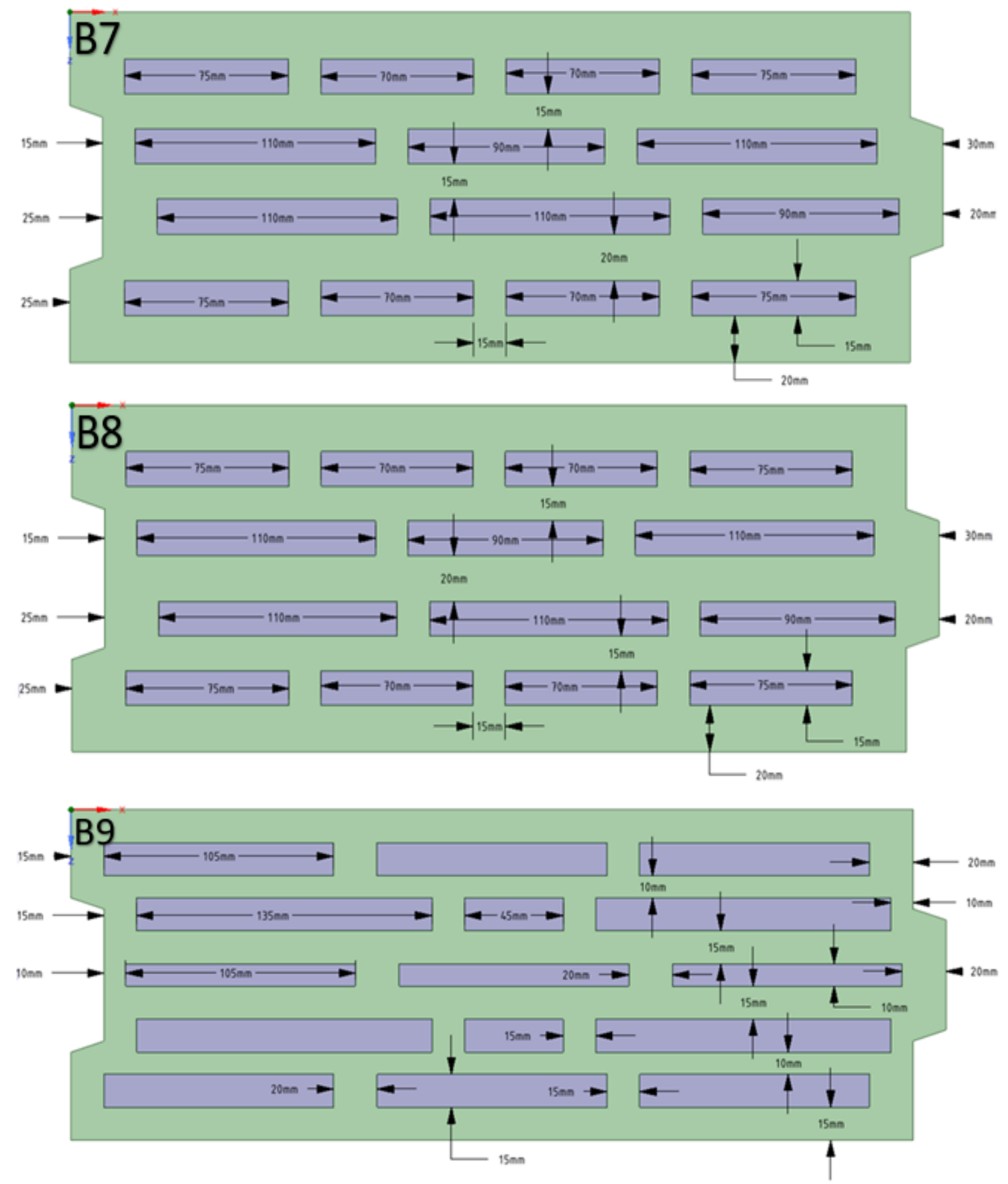

Figure 4. Hollow configurations (B1 to B9) considered in the first part of optimisation research

Mass in another point evaluated along with the thermal insulation performance for the scenarios taken into consideration within the scope of the present work. The research aims at not only producing highly thermally resistive bricks through geometric optimisation but also proposing a lightweight building element design for the future of masonry walls. From this point of view, enhancement in the U-value through the proposed configurations is numerically determined as shown in Table 4 in comparison with the RM and the best design of the first set of optimisations (B9). It is understood from the findings of 5row hollow brick optimisation analyses that the lowest U-value is achieved through the design of B28 with $0.5086 \mathrm{~W} /\left(\mathrm{m}^{2} . \mathrm{K}\right)$. It is followed by B27, B26 and B25 with $0.5149,0.5150$ and $0.5157 \mathrm{~W} /\left(\mathrm{m}^{2} . \mathrm{K}\right)$, respectively. The greatest enhancement in the $\mathrm{U}$-value is found to be $44.51 \%$ compared to the RM. The mass of RM is reported to be $10.44 \mathrm{~kg}$. Although B28 is found having the lowest U-value, it is not the lightest model among the configurations considered. The mass of B28 is calculated to be $8.887 \mathrm{~kg}$. On the other hand, B25 shows the lightest design among all 19 cases with $8.547 \mathrm{~kg}$. The U-value of this lightest configuration is determined to be $0.5157 \mathrm{~W} /\left(\mathrm{m}^{2} . \mathrm{K}\right)$, which is highly competitive with the data 
achieved in B28. The results indicate that B25 provides a $18.13 \%$ lighter building element in comparison to the RM.

Table 4. The improvement in the U-values of 5-row hollow bricks

\begin{tabular}{cccccccc}
\hline Model & Heat transfer rate $(\mathrm{W})$ & $\mathrm{T}_{\max }(\mathrm{K})$ & $\mathrm{T}_{\min }(\mathrm{K})$ & $\Delta \mathrm{T}(\mathrm{K})$ & $\mathrm{U}$-value $\left(\mathrm{W} /\left(\mathrm{m}^{2} . \mathrm{K}\right)\right)$ & Improvement $(\%)$ & Mass $(\mathrm{kg})$ \\
\hline B28 & 0.697 & 297.545 & 278.286 & 19.259 & 0.508 & 44.506 & 8.887 \\
B27 & 0.705 & 297.532 & 278.288 & 19.244 & 0.514 & 43.822 & 9.784 \\
B26 & 0.706 & 297.546 & 278.287 & 19.259 & 0.515 & 43.810 & 8.943 \\
B25 & 0.707 & 297.549 & 278.285 & 19.264 & 0.515 & 43.739 & 8.547 \\
B24 & 0.706 & 297.297 & 278.348 & 18.949 & 0.523 & 42.881 & 9.784 \\
B23 & 0.717 & 297.372 & 278.314 & 19.058 & 0.528 & 42.344 & 9.493 \\
B22 & 0.715 & 297.261 & 278.354 & 18.906 & 0.531 & 42.033 & 9.784 \\
B21 & 0.720 & 297.244 & 278.357 & 18.886 & 0.535 & 41.566 & 10.254 \\
B20 & 0.720 & 297.236 & 278.345 & 18.890 & 0.535 & 41.543 & 9.896 \\
B19 & 0.724 & 297.236 & 278.359 & 18.877 & 0.539 & 41.185 & 10.292 \\
B18 & 0.725 & 297.230 & 278.358 & 18.871 & 0.539 & 41.112 & 10.403 \\
B17 & 0.725 & 297.211 & 278.349 & 18.862 & 0.540 & 41.056 & 9.933 \\
B16 & 0.731 & 297.197 & 278.352 & 18.845 & 0.545 & 40.525 & 9.988 \\
B15 & 0.731 & 297.195 & 278.352 & 18.843 & 0.545 & 40.521 & 9.988 \\
B14 & 0.734 & 297.214 & 278.348 & 18.865 & 0.546 & 40.345 & 9.574 \\
B13 & 0.735 & 297.184 & 278.353 & 18.831 & 0.548 & 40.144 & 10.366 \\
B12 & 0.735 & 297.170 & 278.355 & 18.814 & 0.548 & 40.146 & 10.366 \\
B11 & 0.740 & 297.158 & 278.358 & 18.800 & 0.553 & 39.625 & 10.403 \\
B9 & 0.755 & 297.135 & 278.359 & 18.776 & 0.564 & 38.384 & 10.527 \\
B10 & 0.762 & 297.043 & 278.379 & 18.664 & 0.573 & 37.429 & 11.183 \\
RM & 1.157 & 296.252 & 278.524 & 17.728 & 0.916 & 0.0000 & 10.440 \\
\hline
\end{tabular}

It is observed from the preliminary results that 5-row design gives the greatest thermal resistance among the all configurations covering 3 and 4-row option. When compared to the performance figures of RM, B9 provides $38.4 \%$ enhancement in thermal insulation feature. The U-value of this 5-row design given in B9 is determined to be $0.56 \mathrm{~W} /\left(\mathrm{m}^{2} . \mathrm{K}\right)$. Owing to the notably better thermal behaviour of $\mathrm{B} 9$, the second part of the optimization analyses is based on the different combinations of 5-row design for further potential improvements. 19 more hollow configurations are analysed in the second part as demonstrated in Figure 5.

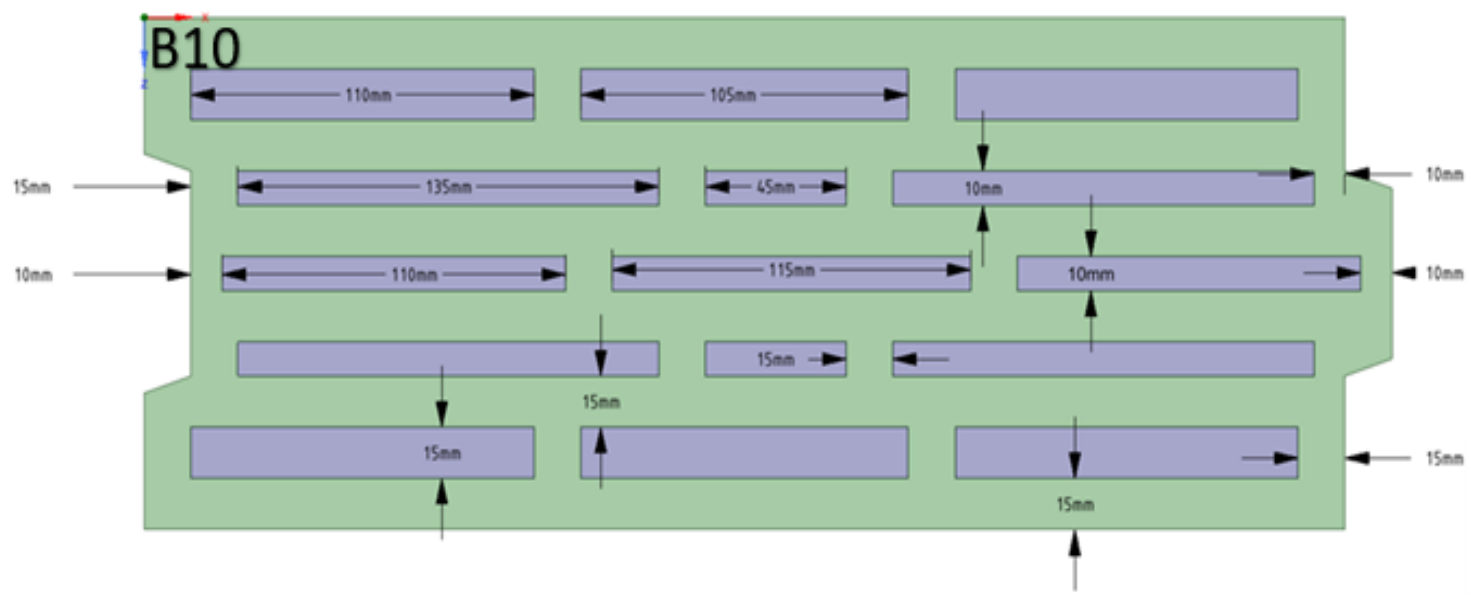

Figure 5. Continues 

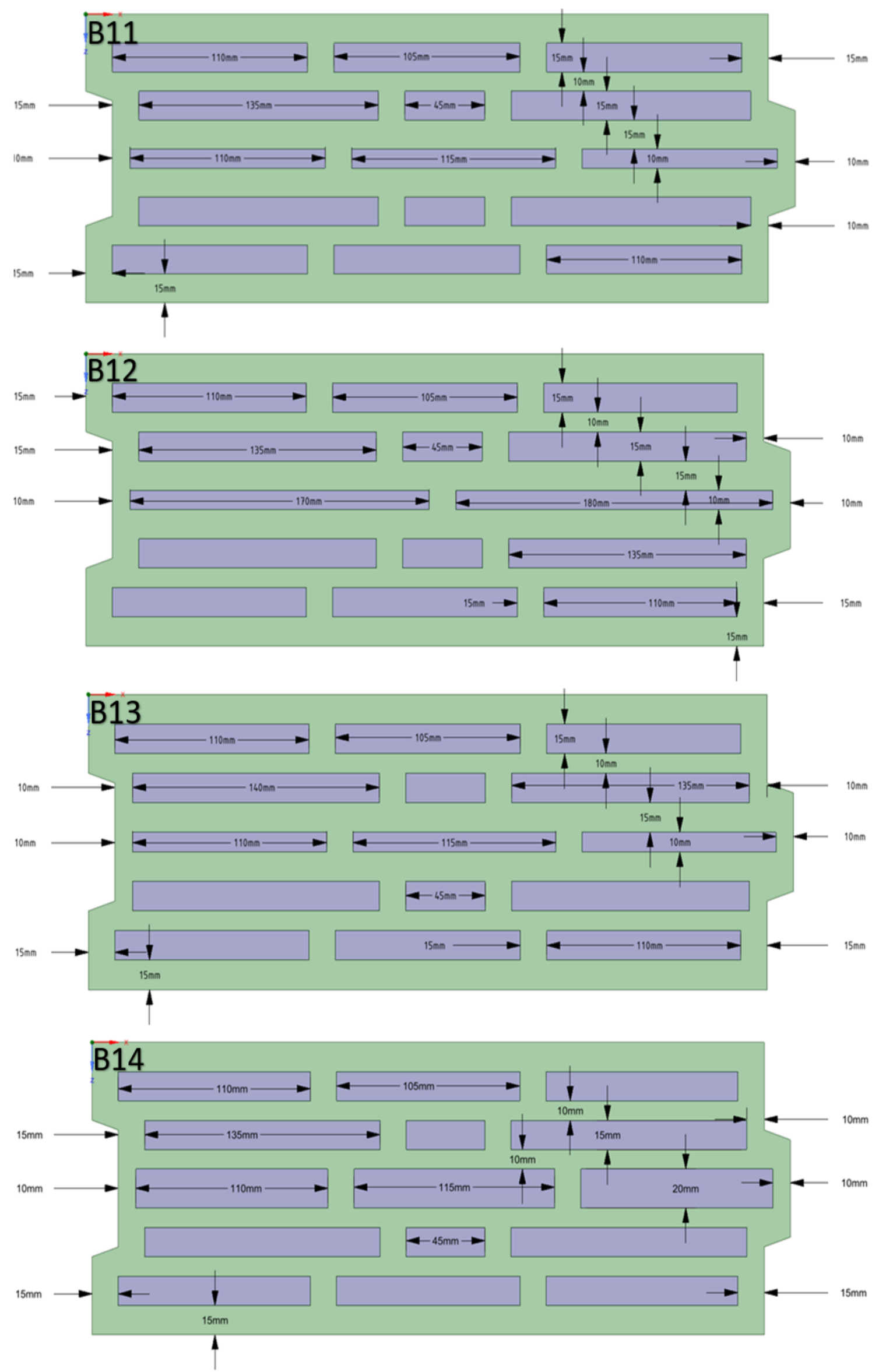

Figure 5. Continues 

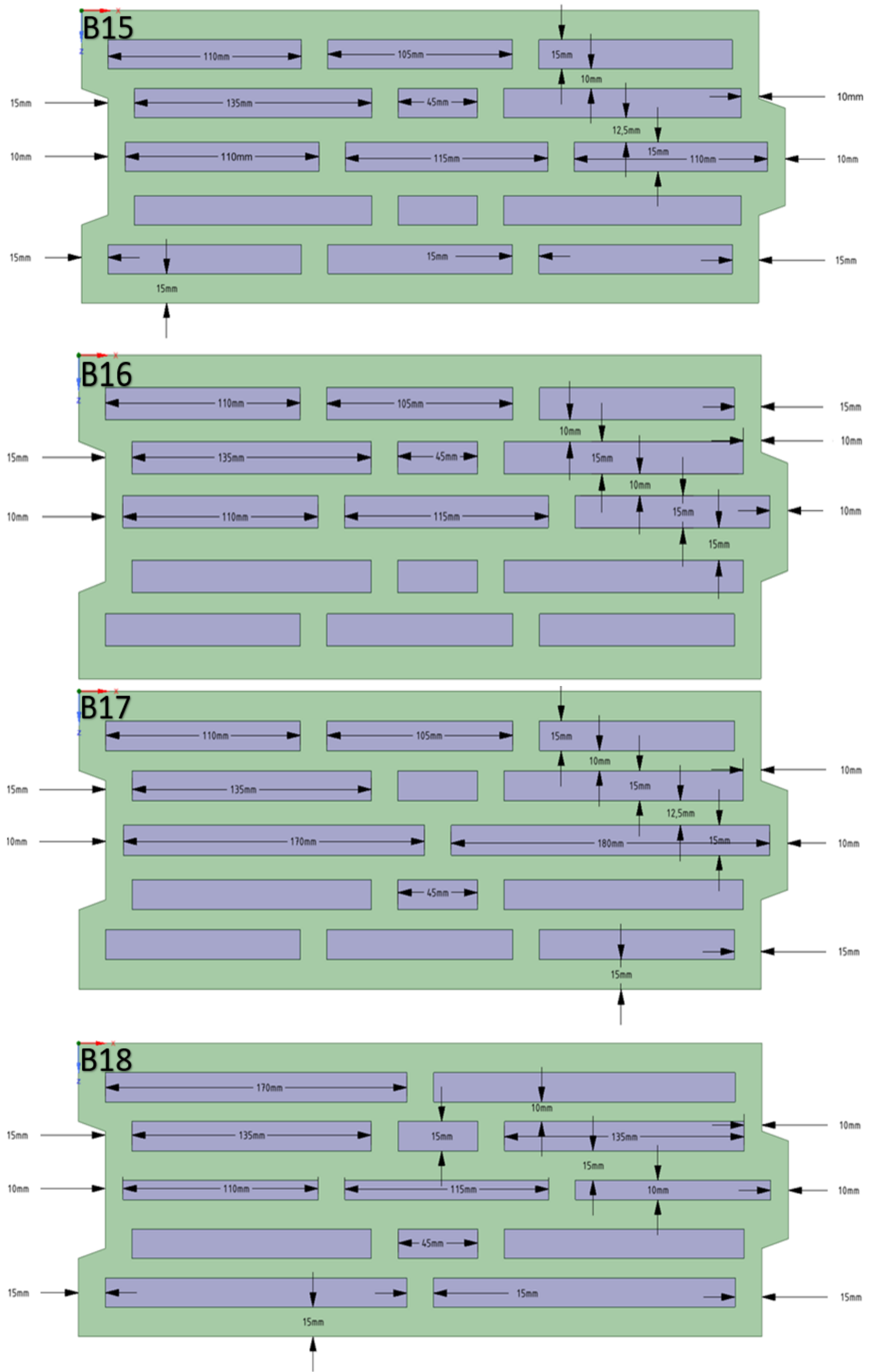

Figure 5. Continues 

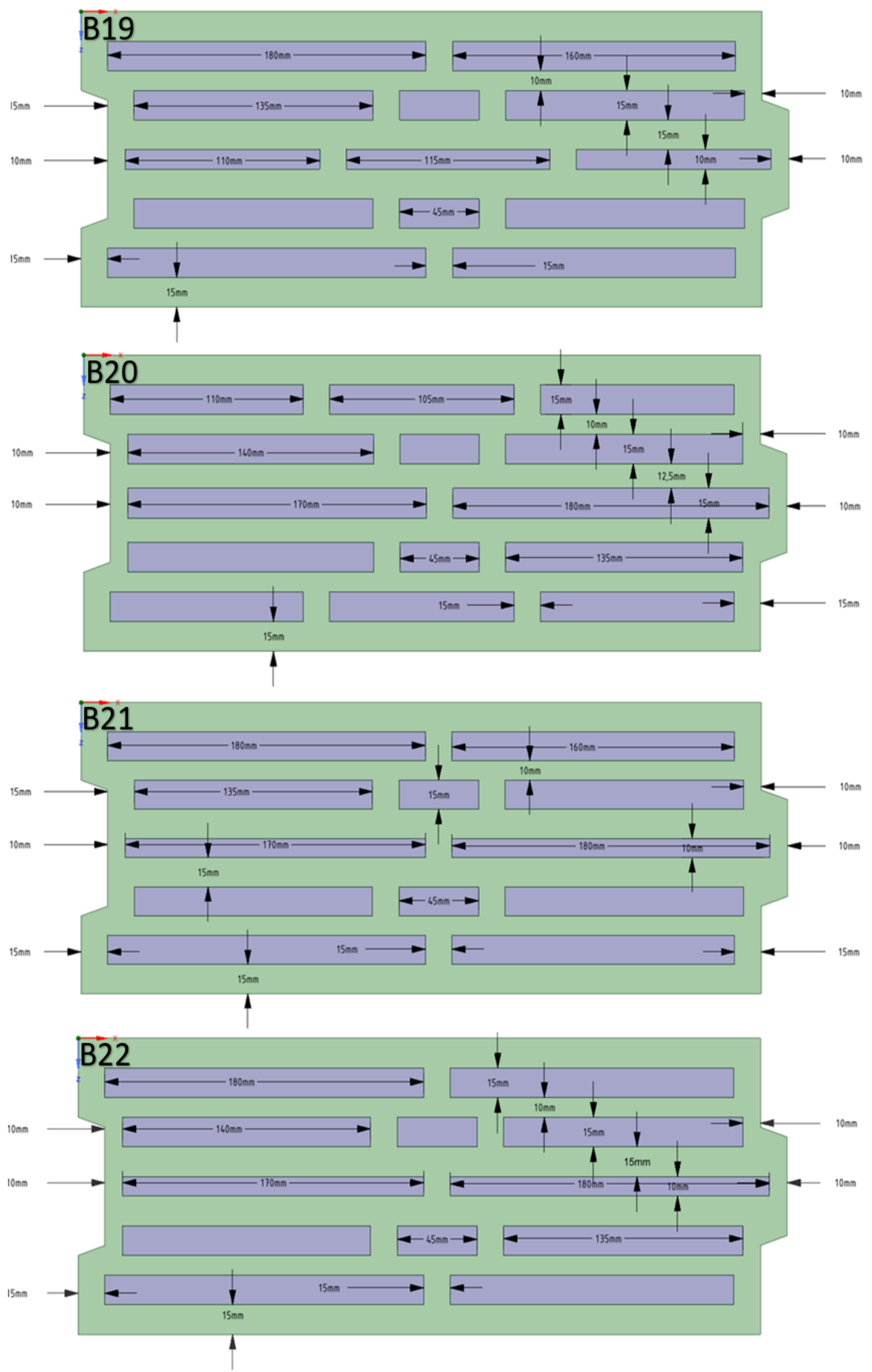

Figure 5. Continues 


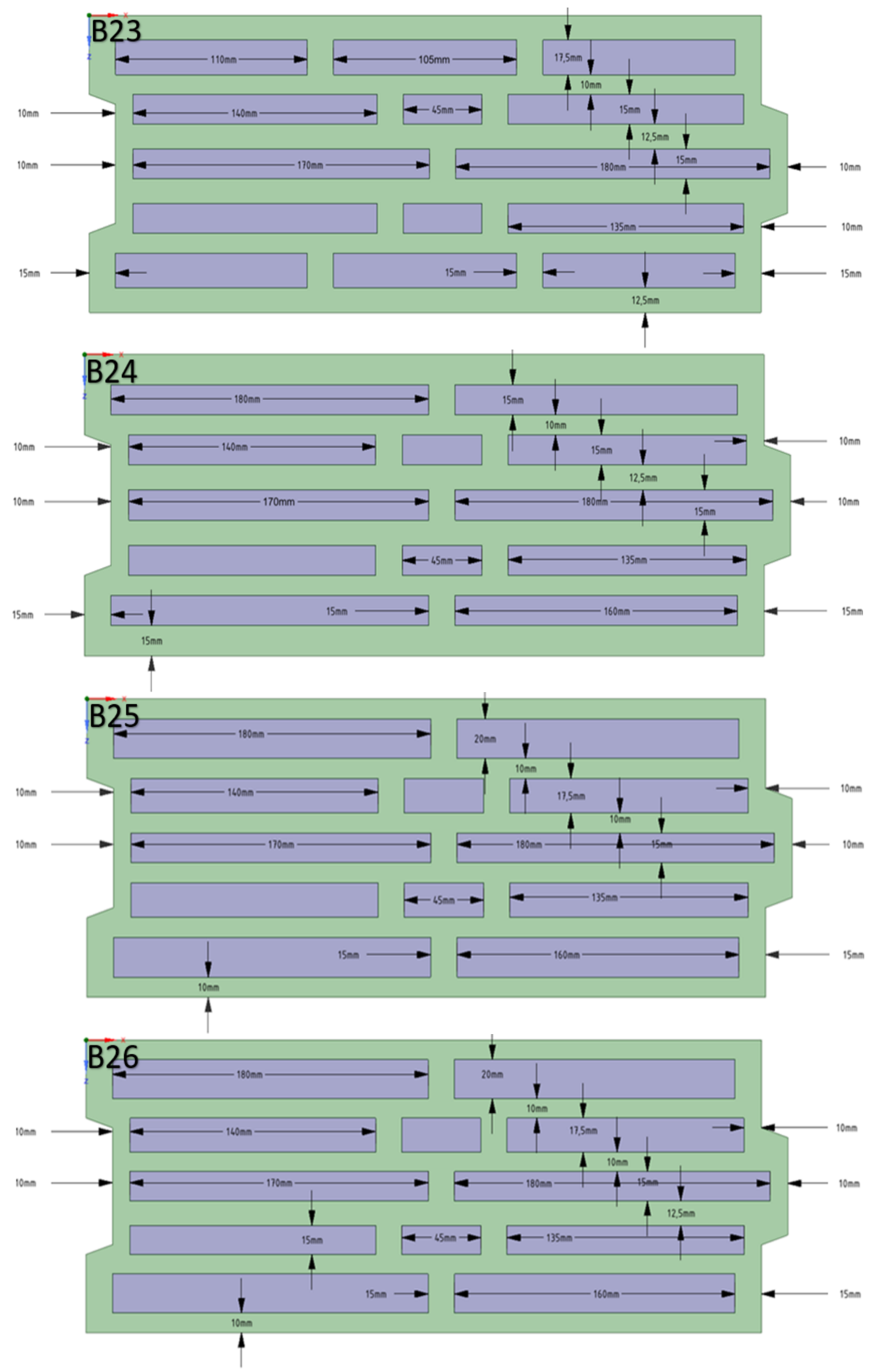

Figure 5. Continues 

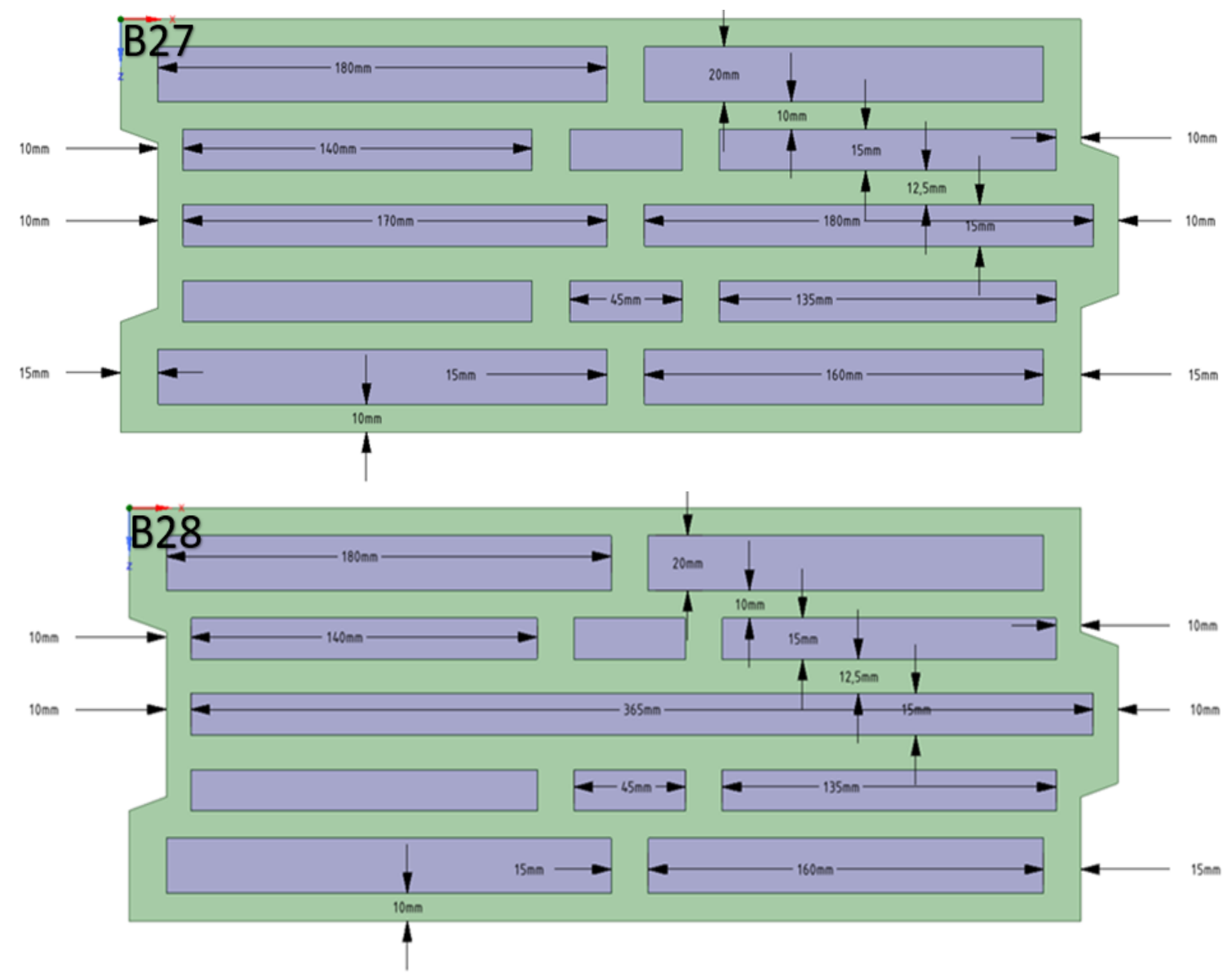

Figure 5. Different 5-row hollow designs (B10 to B28) for the second part of optimisation research.

The aforesaid configurations are proposed through the physical principles of heat transfer mechanisms of conduction and natural convection. By doing so, a relatively more resistive layer is considered closer to the indoor environment, in other words to the hot side. Then, a loose medium in terms of thermal resistance welcomes the transmitted heat. In the middle of the building element, again a highly thermally resistive layer is considered for a drastic mitigation of heat flow. A symmetric structure then is adopted till the cold side for an optimum reduction in the U-value.

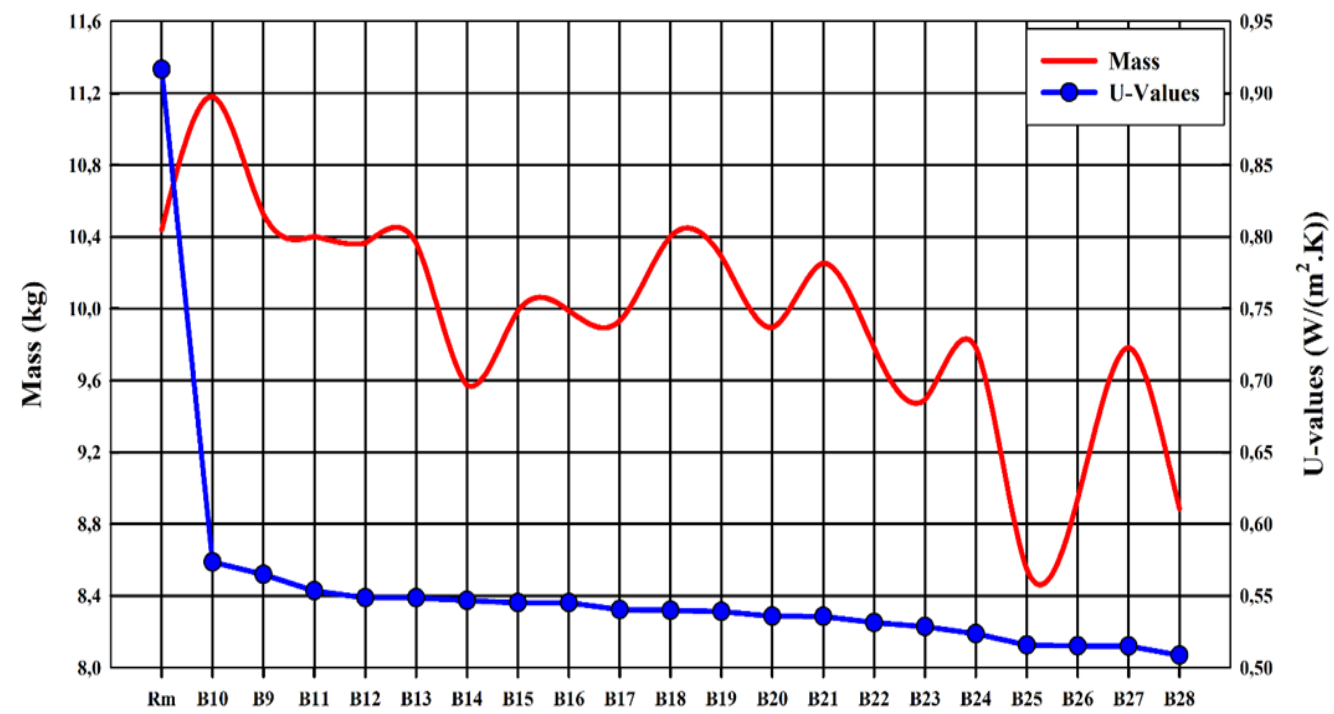

Brick-Configurations

Figure 6. Mass and U-values of 5-row hollow designs (B10 to B28) in comparison with the RM. 
It is perspicuous from Figure 6 that the mass and U-values of 19 different 5-row hollow designs are required to be optimised for an appropriate configuration for further optimisation analyses concerning the height ratio of hollows. The results reveal that the lightest design is achieved by B25 whereas the lowest U-value is enabled by B28. In the meantime, it is understood that B23, B26 and B27 are another suitable design among the all configurations when the thermal resistance and lightness are taken into consideration at the same time. In this respect, B23, B25, B26, B27 and B28 are considered as the optimal cases in terms of mass and U-value prior to the optimisation of hollow depth in the concrete bricks.

\subsection{The Height Ratio of Hollow}

Through the first and second part of the optimisation research, it is achieved that the configurations of B23, B25, B26, B27 and B28 represent the optimum designs in terms of both U-value and mass. Therefore, the aforesaid cases are taken into consideration for further improvements of U-value and mass by optimising the height ratio of hollow in concrete bricks. At RMB, the height of hollows is reported to be $165 \mathrm{~mm}$ whereas the entire height of the brick is $180 \mathrm{~mm}$. In this respect, it is possible to expand the hollow height up to $180 \mathrm{~mm}$ at RMB. The hollow height is increased by $5 \mathrm{~mm}$ at each stage, and the improvement in the U-value is evaluated in comparison with B9 and RM as shown in Table 5. It is understood from the findings that the $\mathrm{U}$-value of concrete bricks proportionally reduces with the height ratio of hollow $(\mathrm{h} / \mathrm{H})$ as depicted in Figure 7. This can be ascribed to the notably lower thermal conductivity of air than that of brick material. Relatively greater air volumes within the entire brick yield to higher thermal resistance thus lower U-values as can be expected. When the improvement in the Uvalues compared to the RM is evaluated, it is observed that the greatest enhancement is achieved by B48 with $52.9 \%$ as illustrated in Figure 8.

\subsection{The Weight of Concrete Brick}

Concrete bricks are still challenging for buildings since they cause undesired extra weight to external walls. In this respect, reducing unit mass of concrete bricks through geometric optimisation while improving thermal insulation performance is of vital importance for lightweight concrete hollow bricks. Therefore, this research also targets to highlight the effects of brick mass on the thermal behaviour of the said building elements.

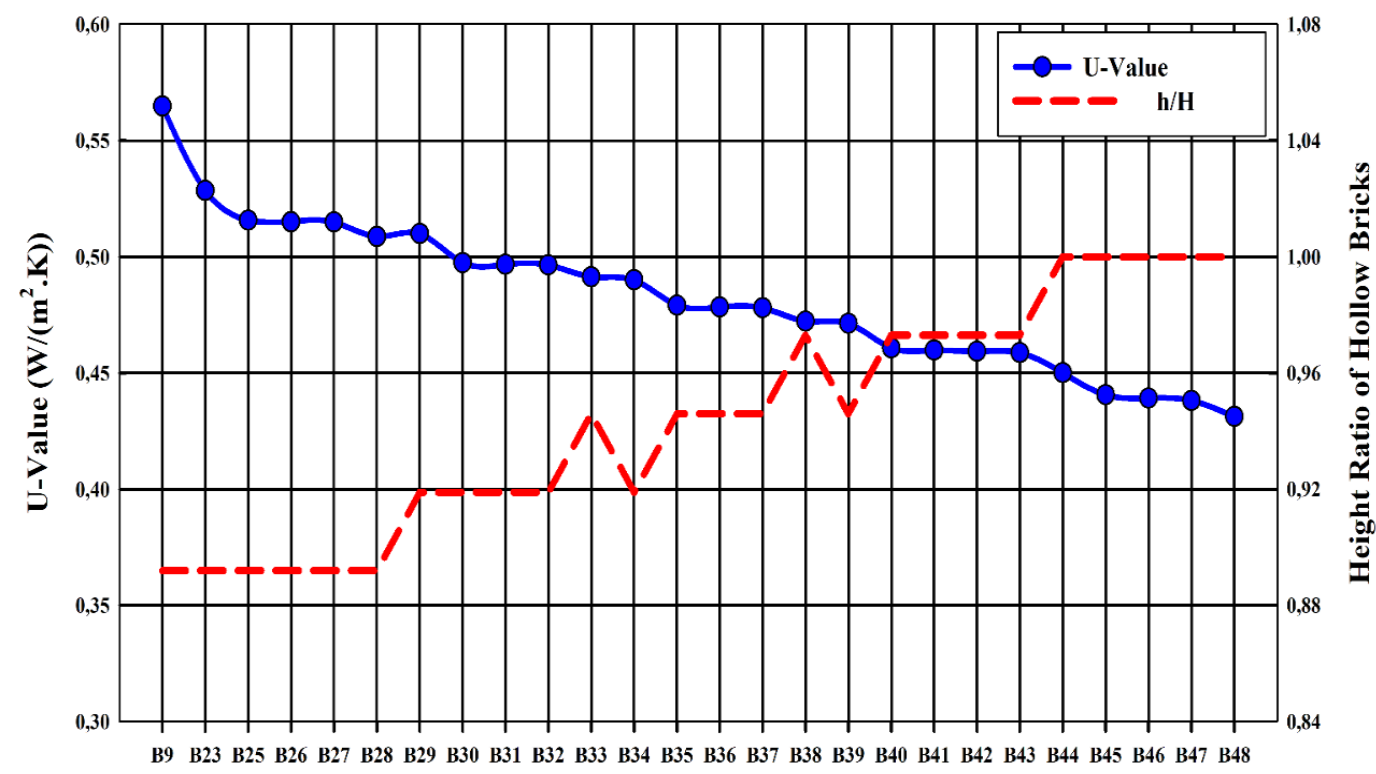

Brick-Configurations

Figure 7. The influence of height ratio of hollow $(h / H)$ on thermal behaviour of concrete bricks. 


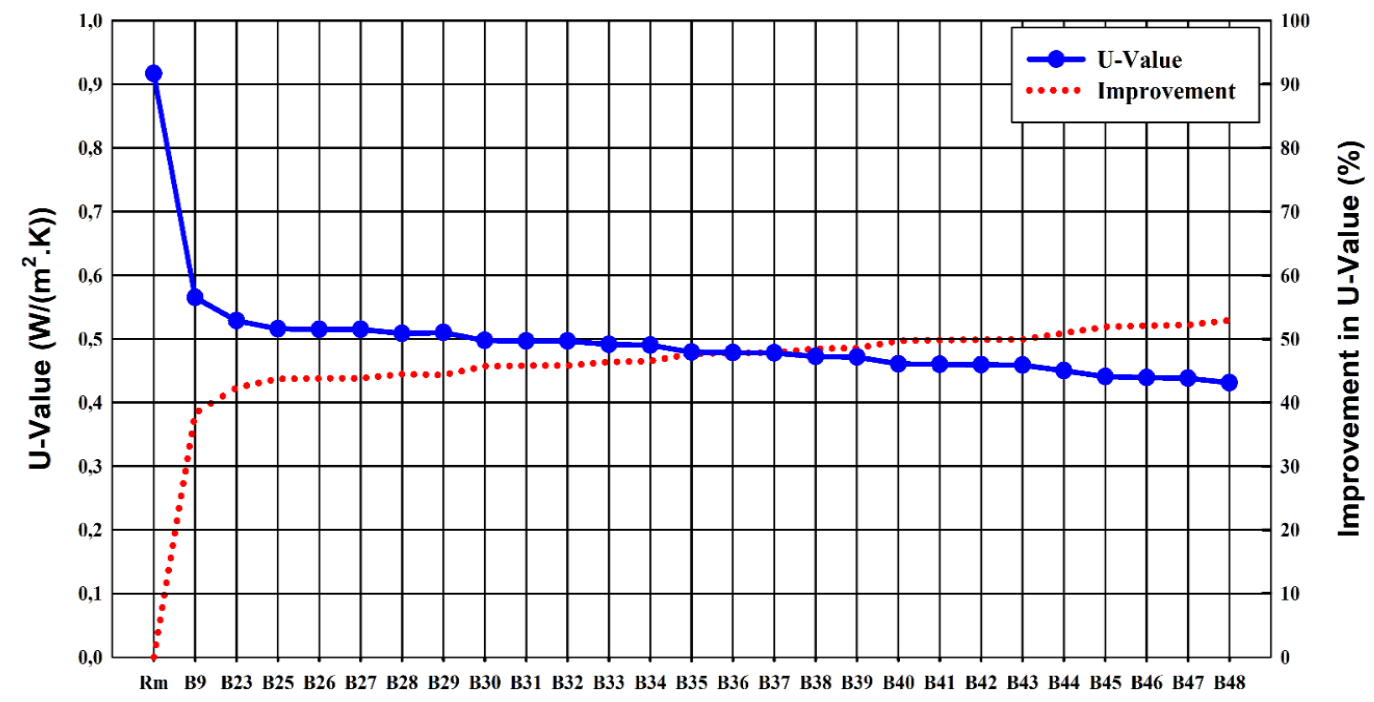

Brick-Configurations

Figure 8. Enhancement in the U-value of concrete bricks by optimising of height ratio of hollows.

Table 5. The improvement in the U-values with the rise in hollow height

\begin{tabular}{|c|c|c|c|c|c|c|c|c|}
\hline Model & Heat transfer rate $(\mathrm{W})$ & $\mathrm{T}_{\max }(\mathrm{K})$ & $\mathrm{T}_{\min }(\mathrm{K})$ & $\Delta \mathrm{T}(\mathrm{K})$ & U-value $\left(\mathrm{W} /\left(\mathrm{m}^{2} . \mathrm{K}\right)\right)$ & $\mathrm{h}(\mathrm{mm})$ & $\mathrm{h} / \mathrm{H}$ & Improvement (\%) \\
\hline RM & 1.157 & 296.252 & 278.524 & 17.729 & 0.916 & 165.0 & 0.892 & 0.000 \\
\hline B9 & 0.755 & 297.135 & 278.359 & 18.776 & 0.564 & 165.0 & 0.892 & 38.380 \\
\hline B23 & 0.717 & 297.372 & 278.314 & 19.058 & 0.528 & 165.0 & 0.892 & 42.345 \\
\hline B25 & 0.707 & 297.549 & 278.285 & 19.264 & 0.515 & 165.0 & 0.892 & 43.739 \\
\hline B26 & 0.706 & 297.547 & 278.288 & 19.259 & 0.515 & 165.0 & 0.892 & 43.810 \\
\hline B27 & 0.705 & 297.533 & 278.288 & 19.245 & 0.514 & 165.0 & 0.892 & 43.823 \\
\hline B28 & 0.692 & 297.381 & 278.309 & 19.072 & 0.510 & 170.0 & 0.919 & 44.360 \\
\hline B29 & 0.697 & 297.546 & 278.287 & 19.259 & 0.508 & 165.0 & 0.892 & 44.506 \\
\hline B30 & 0.683 & 297.559 & 278.279 & 19.280 & 0.497 & 170.0 & 0.919 & 45.733 \\
\hline B31 & 0.681 & 297.556 & 278.282 & 19.275 & 0.496 & 170.0 & 0.919 & 45.810 \\
\hline B32 & 0.681 & 297.543 & 278.282 & 19.260 & 0.496 & 170.0 & 0.919 & 45.833 \\
\hline B33 & 0.667 & 297.388 & 278.301 & 19.087 & 0.491 & 175.0 & 0.946 & 46.394 \\
\hline B34 & 0.672 & 297.555 & 278.281 & 19.275 & 0.490 & 170.0 & 0.919 & 46.537 \\
\hline B35 & 0.658 & 297.567 & 278.270 & 19.297 & 0.479 & 175.0 & 0.946 & 47.725 \\
\hline B36 & 0.657 & 297.564 & 278.274 & 19.291 & 0.478 & 175.0 & 0.946 & 47.811 \\
\hline B37 & 0.656 & 297.551 & 278.274 & 19.276 & 0.478 & 175.0 & 0.946 & 47.846 \\
\hline B38 & 0.642 & 297.395 & 278.288 & 19.107 & 0.472 & 180.0 & 0.973 & 48.476 \\
\hline B39 & 0.647 & 297.563 & 278.273 & 19.291 & 0.471 & 175.0 & 0.946 & 48.572 \\
\hline B40 & 0.633 & 297.574 & 278.256 & 19.318 & 0.460 & 180.0 & 0.973 & 49.730 \\
\hline B41 & 0.632 & 297.572 & 278.260 & 19.312 & 0.459 & 180.0 & 0.973 & 49.831 \\
\hline B42 & 0.631 & 297.558 & 278.261 & 19.297 & 0.459 & 180.0 & 0.973 & 49.892 \\
\hline B43 & 0.622 & 297.571 & 278.523 & 19.048 & 0.458 & 180.0 & 0.973 & 49.955 \\
\hline B44 & 0.614 & 297.402 & 278.231 & 19.171 & 0.450 & 185.0 & 1.000 & 50.899 \\
\hline B45 & 0.608 & 297.581 & 278.205 & 19.376 & 0.440 & 185.0 & 1.000 & 51.929 \\
\hline B46 & 0.606 & 297.579 & 278.207 & 19.372 & 0.439 & 185.0 & 1.000 & 52.083 \\
\hline B47 & 0.604 & 297.566 & 278.207 & 19.359 & 0.438 & 185.0 & 1.000 & 52.195 \\
\hline B48 & 0.595 & 297.578 & 278.206 & 19.372 & 0.431 & 185.0 & 1.000 & 52.949 \\
\hline
\end{tabular}

According to the results, the minimum brick mass is achieved from B45 design as shown in Figure 9, and the improvement in the U-value belonging to the brick is about $1 \%$ lower than the maximum improvement. On the other hand, an illustrative comparison of bricks in the final part of the optimisation research is done for the unit mass as depicted in Table 6 (APPENDIX A). The results reveal that the $\mathrm{h} / \mathrm{H}$ ratio considerably affects the weight of concrete bricks. When the all scenarios are taken into consideration, B45 and B46 can be accepted as the optimum design since these bricks provide both notably better thermal resistance and remarkably lighter building element. The enhancement in the mass reduction is found to be 24.64 and $26.77 \%$ for B46 and B45, respectively. If there is an obstacle to use perforated bricks, then 5-row hollow brick design is found the most appropriate configuration in terms of thermal insulation performance. In this respect, B9, B25, B26 and B28 can be considered as optimal cases. The improvement in thermal resistance of B25, B26 and B28 is determined to be 43.7, 43.8, and $44.5 \%$ compared to the RM. Static contours of temperature within the aforesaid brick designs are given in Figure 10. 
For readers' interest, an additional numerical research is carried out to evaluate the potential role of radiation as a heat transfer mechanism in total heat transfer rate from brick to ambient and surrounding environment. The findings of calculations based on Stefan-Boltzmann Law reveal that radiation-related heat transfer rate is $0.11 \mathrm{~W}$ whereas the total heat transfer rate is $1.157 \mathrm{~W}$ for the said case. In other words, radiation-based heat transfer accounts for about $8.7 \%$ of total heat dissipation. From this point of view, radiation is not considered in the governing equations. The characteristic results of the present research indicate that thermal resistance of hollow bricks can be improved through the geometric optimisation of hollows. By doing so, U-value of lightweight concrete hollow bricks can be decreased by about $44 \%$ when thermal resistance and brick weight are simultaneously taken into consideration. It is because of the control of natural convection within the cavities, and in different works, similar tendencies are observed. It is reported in such a research [34] that heat flux across the hollow bricks can be mitigated by $37-42 \%$ via the effective control of natural convection.

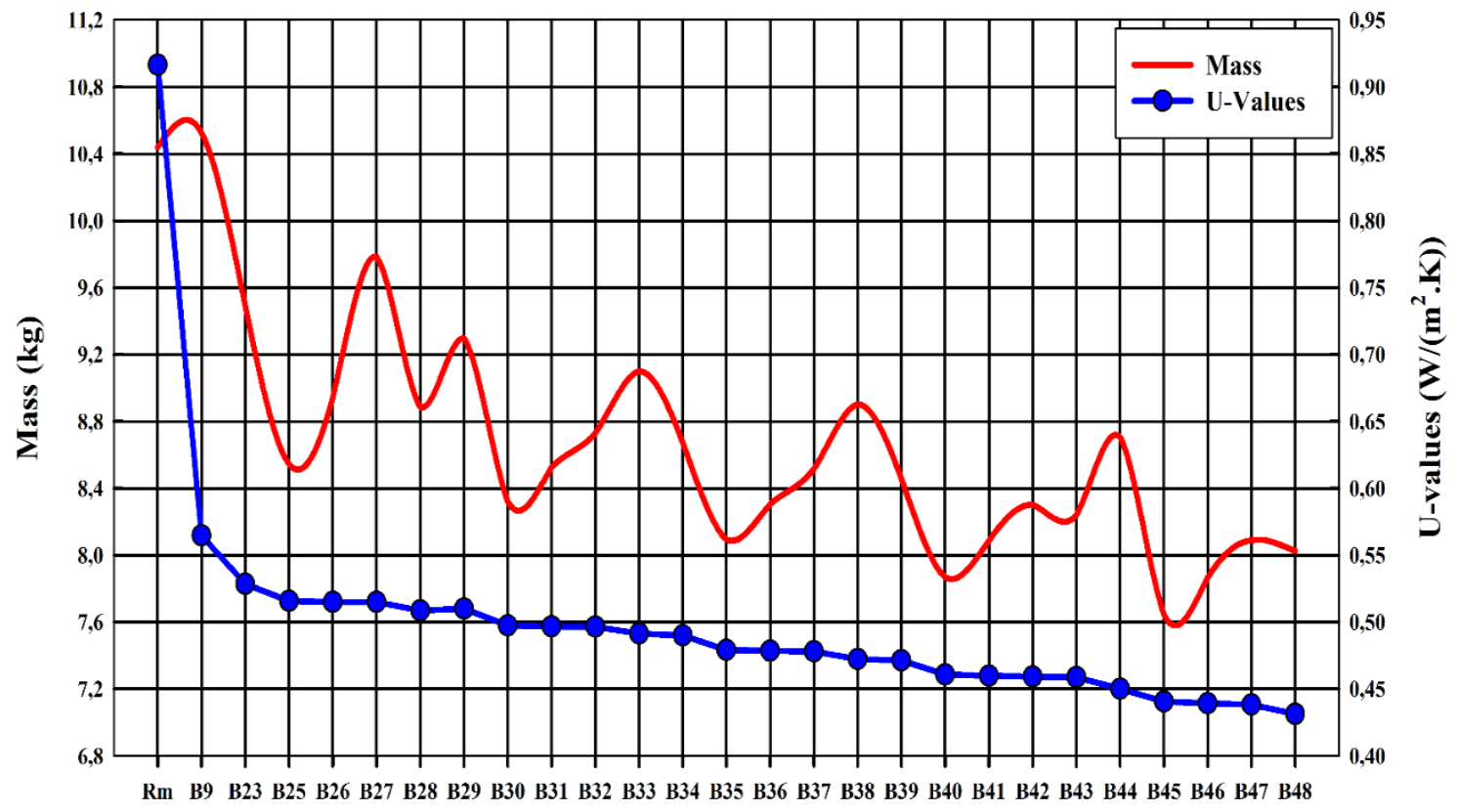

Brick-Configurations

Figure 9. The relationship between the $U$-value and the mass of concrete bricks.

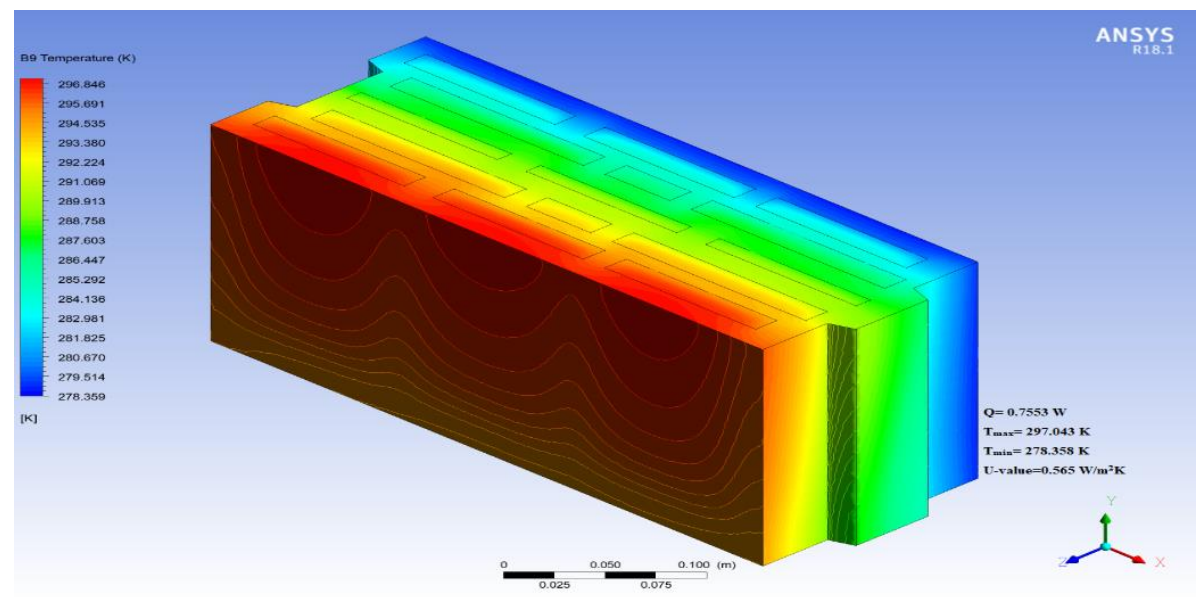

Figure 10. Continue 

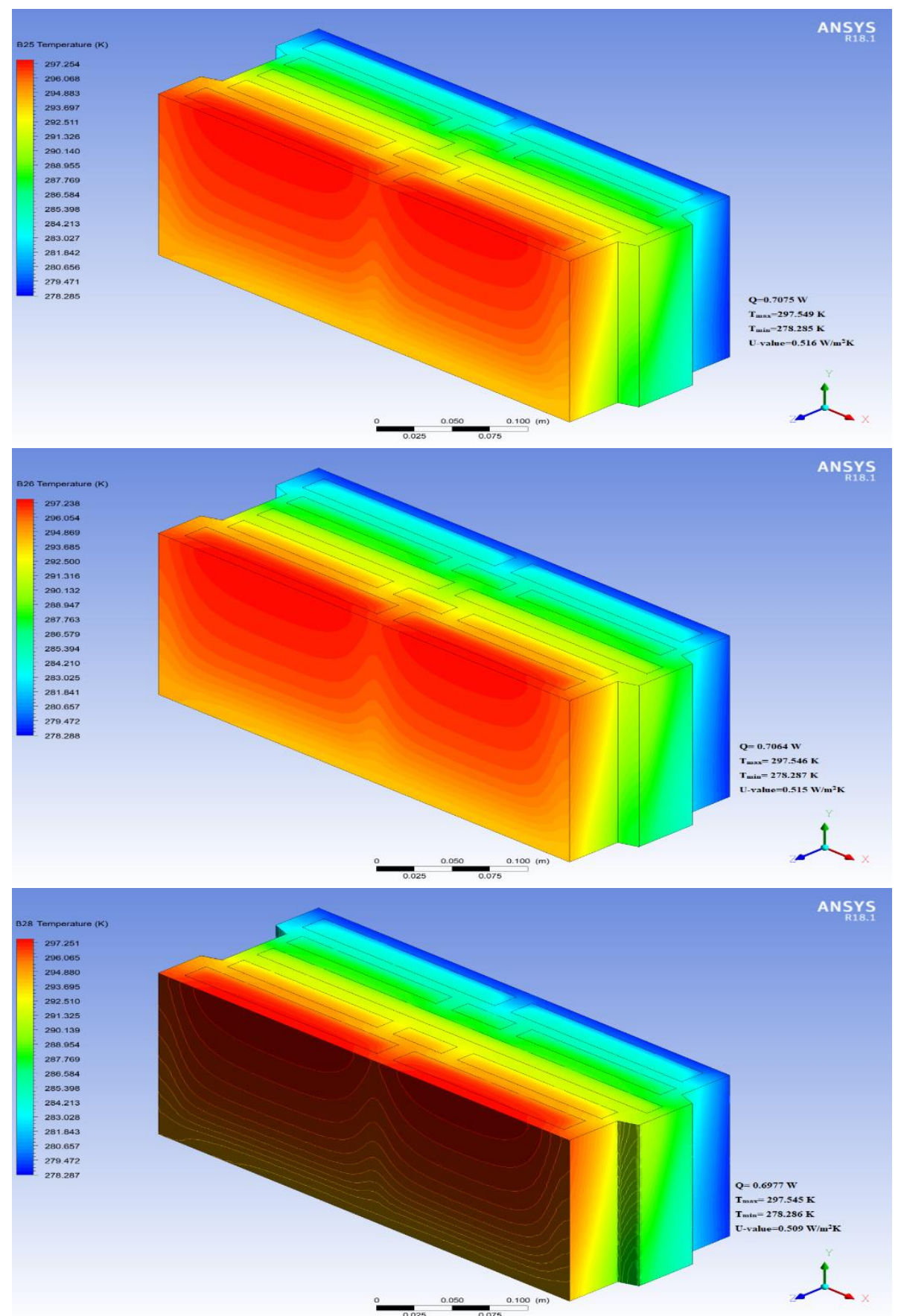

Figure 10. Temperature gradients with regard to B9, B25, B26 and B28

\section{CONCLUSION}

This research aims at carrying out geometric optimisation for concrete hollow bricks for a more thermally resistive and lighter building element configuration. A commercially available concrete brick is considered as reference model in the numerical research, and optimisation is conducted for several parameters such as number of hollow rows, height ratio of hollows and weight of bricks. The results reveal that increasing number of hollow rows remarkably enhances the thermal resistance of hollow bricks. The improvement in the U-value of bricks is found to be in the range of 20-53\% compared to the RM. The results also indicate that hollow depth notably reduces the U-value and the unit weight, which is the goal of this numerical research. Following bullet points can be achieved through the study: 
Among 3, 4 and 5-row hollow designs, the best configuration is obtained from the 5-row cases in terms of both thermal resistance and lightness. Geometric optimisation analyses reveal that the lowest enhancement in the U-value is observed in B1 with $20.27 \%$ whereas the greatest improvement is achieved by B48 with $52.95 \%$.

The minimum brick mass is observed in B45 with $7.645 \mathrm{~kg}$ whereas the mass of RM is $10.44 \mathrm{~kg}$. In other words, B45 is capable of providing about $26.8 \%$ lighter concrete hollow brick than the RM.

When both U-value and brick weight are taken into consideration, B45 and B46 can be asserted as the optimum design.

Through the numerical analyses, the maximum enhancement is found to be about 53\% (U-value 0.43 $\left.\mathrm{W} /\left(\mathrm{m}^{2} . \mathrm{K}\right)\right)$ by the design of B48 which has an h-ratio of 1 (perforated brick). Moreover, depending on the increase in h-ratio, it is achieved that the thermal performance of the bricks proportionally increases. For the lightest configuration (B45), U-value is determined as $0.44 \mathrm{~W} /\left(\mathrm{m}^{2} . \mathrm{K}\right)$.

In further studies, thermal performance of some chosen bricks depending on the findings from this study can be experimentally investigated and the results from numerical and experimental analyses can be compared.

\section{REFERENCES}

[1] Besir, AB, Cuce, E. Green roofs and facades: A comprehensive review. Renewable and Sustainable Energy Reviews 2018; 82(1): 915-939.

[2] Martínez, MA, Tort, AI, Cho, S, Vivancos, JL. Energy efficiency and thermal comfort in historic buildings: A review. Renewable and Sustainable Energy Reviews 2016; 61: 70-85.

[3] IEA. Tracking Buildings https://www.iea.org/reports/tracking-buildings; 2019 [accessed May 14, 2020].

[4] Raji, B, Tenpierik, MJ, Van Den Dobbelsteen, A. An assessment of energy-saving solutions for the envelope design of high-rise buildings in temperate climates: A case study in the Netherlands. Energy Buildings 2016; 124: 201-221.

[5] Guo, Q, Wu Y, Ding, Y, Feng, W, Zhu, N. Measures to enforce mandatory civil building energy efficiency codes in China. Journal of Cleaner Production 2016; 119: 152-166.

[6] Peuportier, B, Thiers, S, Guiavarch, A. Eco-design of buildings using thermal simulation and life cycle assessment. Journal of Cleaner Production 2013; 39: 73-8.

[7] De Boeck, L, Verbeke, S, Audenaert, A, De Mesmaeker, L. Improving the energy performance of residential buildings: A literature review. Renewable and Sustainable Energy Reviews 2015; 52: 960-975.

[8] Kampelis, N, Gobakis, K, Vagias, V, Kolokotsa, D, Standardi, L, Isidori D, et al. Evaluation of the performance gap in industrial, residential \& tertiary near-Zero energy buildings. Energy and Buildings 2017; 148: 58-73.

[9] Cuce, E, Cuce, PM, Wood, CJ, Riffat, SB. Optimizing insulation thickness and analysing environmental impacts of aerogel-based thermal superinsulation in buildings. Energy and Buildings 2014; 77: 28-39.

[10] Cuce, E, Riffat, SB. Aerogel-assisted support pillars for thermal performance enhancement of vacuum glazing: A CFD research for a commercial product. Arabian Journal for Science and Engineering 2015; 40(8): 2233-2238.

[11] Cuce, E, Cuce, PM, Young, CH. Energy saving potential of heat insulation solar glass: Key results from laboratory and in-situ testing. Energy 2016; 97: 369-380.

[12] Cuce, E, Riffat, SB. Vacuum tube window technology for highly insulating building fabric: An experimental and numerical investigation. Vacuum 2015; 111: 83-91.

[13] Cuce, E, Cuce, PM. The impact of internal aerogel retrofitting on the thermal bridges of residential buildings: An experimental and statistical research. Energy and Buildings 2016; 116: 449-454.

[14] Cuce, E. Toward multi-functional PV glazing technologies in low/zero carbon buildings: Heat insulation solar glass - Latest developments and future prospects. Renewable and Sustainable Energy Reviews 2016; 60: 12861301.

[15] Cuce, E. Development of innovative window and fabric technologies for low-carbon buildings. Ph.D. Thesis, The University of Nottingham, UK, 2014. 
[16] Del Coz Díaz, JJ, García Nieto, PJ, Domínguez Hernández, J, Álvarez Rabanal, FP. A FEM comparative analysis of the thermal efficiency among floors made up of clay, concrete and lightweight concrete hollow blocks. Applied Thermal Engineering 2010; 30: 2822-2826.

[17] Costa, VAF. Improving the thermal performance of red clay holed bricks. Energy and Buildings 2014; 70: $352-364$

[18] Antoniadis, KD, Assael, MJ, Tsiglifisi, CA, Mylona, SK. Improving the design of Greek hollow clay bricks. International Journal of Thermophysics 2012; 33: 2274-2290.

[19] Del Coz Díaz, JJ, García Nieto, PJ, Díaz Pérez, LM, Riesgo Fernández, P. Nonlinear thermal analysis of multi-holed lightweight concrete blocks used in external and non-habitable floors by FEM. International Journal of Heat and Mass Transfer 2011; 54: 533-548.

[20] Cuce, E. Role of airtightness in energy loss from windows: Experimental results from in-situ tests. Energy and Buildings 2017; 139: 449-455

[21] Morales, MP, Juárez, MC, Muñoz, P, Gómez, JA. Study of the geometry of a voided clay brick using nonrectangular perforations to optimise its thermal properties. Energy and Buildings 2011; 43(9): 2494-2498.

[22] Li, LP, Wu, ZG, He, YL, Lauriat, G, Tao, WQ. Optimization of the configuration of $290 \times 140 \times 90$ hollow clay bricks with 3-D numerical simulation by finite volume method. Energy and Buildings 2008; 40(10): 17901798.

[23] Morales, MP, Juárez, MC, López-Ochoa, LM, Doménech, J. Study of the geometry of a voided clay brick using rectangular perforations to optimize its thermal properties. Applied Thermal Engineering 2011; 31(11): 2063-2065.

[24] Sun, J, Fang, L, Han, J. Optimization of concrete hollow brick using hybrid genetic algorithm combining with artificial neural networks. International Journal of Heat and Mass Transfer 2010; 53(23): 5509-5518.

[25] del Coz Díaz, JJ, García Nieto, PJ, Suárez Sierra, JL, Peñuelas Sánchez, I. Non-linear thermal optimization and design improvement of a new internal light concrete multi-holed brick walls by FEM. Applied Thermal Engineering 2008; 28(8-9): 1090-1100.

[26] del Coz Díaz, JJ, García Nieto, PJ, Betegón Biempica, C, Prendes Gero, MB. Analysis and optimization of the heat-insulating light concrete hollow brick walls design by the finite element method. Applied Thermal Engineering 2007; 27(8-9): 1445-1456.

[27] Martínez, M, Huygen, N, Sanders, J, Atamturktur, S. Thermo-fluid dynamic analysis of concrete masonry units via experimental testing and numerical modeling. Journal of Building Engineering 2018; 19: 80-90.

[28] Pavlík, Z, Jerman, M, Fořt, J, Černý, R. Monitoring Thermal Performance of Hollow Bricks with Different Cavity Fillers in Difference Climate Conditions. International Journal of Thermophysics 2015; 36: 557-568.

[29] Del Coz Diaz, JJ, Garcia Nieto, PJ, Martin Rodriguez, A, Lazona Nartinez-Luengas, A, Betegon Biempica, C. Non-linear thermal analysis of light concrete hollow brick walls by the finite element method and experimental validation. Applied Thermal Engineering 2006; 26: 777-786.

[30] Del Coz Diaz, JJ, Garcia Nieto, PJ, Alvarez Rabanal, FP, Dominguez Hernandez, J. Non-linear thermal analysis of the efficiency of light concrete multi-holed bricks with large recess by FEM. Applied Mathematics and Computation 2012; 218: 10040-10049.

[31] Del Coz Diaz, JJ, Garcia-Nieto, PJ, Alvarez-Rabanall, FP, Alonso-Martínez, M, Dominguez-Hernandez, J, Perez-Bella, JM. The use of response surface methodology to improve the thermal transmittance of lightweight concrete hollow bricks by FEM. Construction and Building Materials 2014; 52: 331-344.

[32] Bi-Chao, YE, Zhou, H. Thermal performance analysis of concrete small hollow block. 9th Edition of the International SOLARIS Conference, 30-31 August 2018, Chengdu, China.

[33] Al-Tamimi, AS, Al-Osta, MA, Al-Amoudi, OSB, Ben-Mansour, R. Effect of Geometry of Holes on Heat Transfer of Concrete Masonry Bricks Using Numerical Analysis. Arabian Journal for Science and Engineering 2017; 42(9): 3733-3749.

[34] Alhazmy, MM. Numerical investigation on using inclined partitions to reduce natural convection inside the cavities of hollow bricks. International Journal of Thermal Sciences 2010; 49(11): 2201-2210.

[35] Al-Hazmy, MM. Analysis of coupled natural convection-conduction effects on the heat transport through hollow building blocks. Energy and Buildings 2006; 38(5): 515-521.

[36] Antar, MA, Baig, H. Conjugate conduction-natural convection heat transfer in a hollow building block. Applied Thermal Engineering 2009; 29(17-18): 3716-3720.

[37] Laaroussi, N, Lauriat, G, Raefat, S, Garoum, M, Ahachad, M. An example of comparison between ISO Norm calculations and full CFD simulations of thermal performances of hollow bricks. Journal of Building Engineering 2017; 11: 69-81.

[38] Arendt, K, Krzaczek, M, Florczuk, J. Numerical analysis by FEM and analytical study of the dynamic thermal behavior of hollow bricks with different cavity concentration. International Journal of Thermal Sciences 2011; 50(8): 1543-1553. 
[39] Coz Díaz, JJ de., Nieto, PJG, Sierra, JLS, Biempica, CB. Nonlinear thermal optimization of external light concrete multi-holed brick walls by the finite element method. International Journal of Heat and Mass Transfer 2008; 51(7-8): 1530-1541.

[40] Li, LP, Wu, ZG, Li, ZY, He, YL, Tao, WQ. Numerical thermal optimization of the configuration of multiholed clay bricks used for constructing building walls by the finite volume method. International Journal of Heat and Mass Transfer 2008; 51(13-14): 3669-3682.

[41] Sun, J, Fang, L. Numerical simulation of concrete hollow bricks by the finite volume method. International Journal of Heat and Mass Transfer 2009; 52(23-24): 5598-5607.

[42] Henrique dos Santos, G, Fogiatto, MA, Mendes, N. Numerical analysis of thermal transmittance of hollow concrete blocks. Journal of Building Physics 2017; 41(1): 7-24. 


\section{APPENDIX 1}

Table 6. The comparison of the lightweight concrete hollow bricks depending on mass

\begin{tabular}{|c|c|c|c|c|c|c|c|c|c|c|}
\hline$\frac{\bar{\nabla}}{\bar{z}}$ & 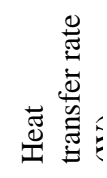 & 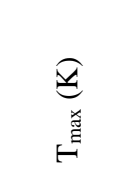 & 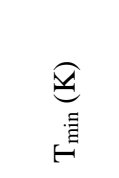 & $\underset{\ddots}{\ddots}$ & 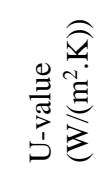 & $\underbrace{\Xi \Xi}_{\beth}$ & $\underset{I}{I}$ & 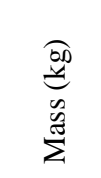 & 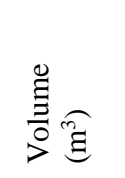 & 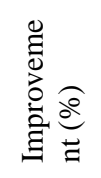 \\
\hline B9 & 0.755 & 297.135 & 278.359 & 18.776 & 0.5648 & 165.0 & 0.892 & 10.527 & 0.00702 & -0.830 \\
\hline $\mathrm{RM}$ & 1.157 & 296.252 & 278.524 & 17.729 & 0.9166 & 165.0 & 0.892 & 10.440 & 0.00696 & 0.000 \\
\hline B27 & 0.705 & 297.533 & 278.288 & 19.245 & 0.5149 & 165.0 & 0.892 & 9.784 & 0.00652 & 6.282 \\
\hline B23 & 0.717 & 297.372 & 278.314 & 19.058 & 0.5285 & 165.0 & 0.892 & 9.493 & 0.00633 & 9.068 \\
\hline B28 & 0.692 & 297.381 & 278.309 & 19.072 & 0.5100 & 170.0 & 0.919 & 9.297 & 0.00620 & 10.952 \\
\hline B33 & 0.667 & 297.388 & 278.301 & 19.087 & 0.4913 & 175.0 & 0.946 & 9.100 & 0.00607 & 12.836 \\
\hline B26 & 0.706 & 297.547 & 278.288 & 19.259 & 0.5150 & 165.0 & 0.892 & 8.943 & 0.00596 & 14.343 \\
\hline B38 & 0.642 & 297.395 & 278.288 & 19.107 & 0.4723 & 180.0 & 0.973 & 8.903 & 0.00594 & 14.720 \\
\hline B29 & 0.697 & 297.546 & 278.287 & 19. & 0.5086 & 16 & 0.892 & 8.887 & 0.00 & 14.876 \\
\hline B32 & 0.681 & 297.543 & 278.282 & 19.260 & 0.4965 & 170.0 & 0.919 & 8.729 & 0.00582 & 16.386 \\
\hline B44 & 0.614 & 297.402 & 278.231 & 19.171 & 0.4501 & 185.0 & 1.000 & 8.707 & 0.00580 & 16.604 \\
\hline B34 & 0.672 & 297.555 & 278.281 & 19.275 & 0.4900 & 170.0 & 0.919 & 8.672 & 0.00578 & 16.936 \\
\hline B25 & 0.707 & 297.549 & 278.285 & 19.264 & 0.5157 & 165.0 & 0.892 & 8.547 & 0.00570 & 18.136 \\
\hline B31 & 0.681 & 297.556 & 278.282 & 19.275 & 0.4967 & 170.0 & 0.919 & 8.525 & 0.00568 & 18.340 \\
\hline B37 & 0.656 & 297.551 & 278.274 & 19.276 & 0.4780 & 175.0 & 0.946 & 8.516 & 0.00568 & 18.430 \\
\hline B39 & 0.647 & 297.563 & 278.273 & 19.291 & 0.4714 & 175.0 & 0.946 & 8.457 & 0.00564 & 18.996 \\
\hline B30 & 0.683 & 297.559 & 278.279 & 19.280 & 0.4974 & 170.0 & 0.919 & 8.321 & 0.00555 & 20.294 \\
\hline B36 & 0.657 & 297.564 & 278.274 & 19.291 & 0.4784 & 175.0 & 0.946 & 8.306 & 0.00554 & 20.442 \\
\hline B42 & 0.631 & 297.558 & 278.261 & 19.297 & 0.4593 & 180.0 & 0.973 & 8.303 & 0.00554 & 20.474 \\
\hline B43 & 0.622 & 297.571 & 278.523 & 19.048 & 0.4587 & 180.0 & 0.973 & 8.242 & 0.00549 & 21.056 \\
\hline B35 & 0.658 & 297.567 & 278.270 & 19.297 & 0.4791 & 175.0 & 0.946 & 8.096 & 0.00540 & 22.453 \\
\hline B47 & 0.604 & 297.566 & 278.207 & 19.359 & 0.4382 & 185.0 & 1.000 & 8.089 & 0.00539 & 22.518 \\
\hline B41 & 0.632 & 297.572 & 278.260 & 19.312 & 0.4598 & 180.0 & 0.973 & 8.087 & 0.00539 & 22.543 \\
\hline B48 & 0.595 & 297.578 & 278.206 & 19.372 & 0.4313 & 185.0 & 1.000 & 8.027 & 0.00535 & 23.116 \\
\hline B40 & 0.633 & 297.574 & 278.256 & 19.318 & 0.4608 & 180.0 & 0.973 & 7.871 & 0.00525 & 24.612 \\
\hline B46 & 0.606 & 297.579 & 278.207 & 19.372 & 0.4392 & 185.0 & 1.000 & 7.867 & 0.00524 & 24.644 \\
\hline B45 & 0.608 & 297.581 & 278.205 & 19.376 & 0.4406 & 185.0 & 1.000 & 7.645 & 0.00510 & 26.771 \\
\hline
\end{tabular}

